UNIVERSITÀ CATTOLICA DEL SACRO CUORE

Dipartimento di Economia e Finanza

\author{
Working Paper Series
}

Deceptive Advertising with Rational Buyers

Salvatore Piccolo, Piero Tedeschi, Giovanni Ursino

Working Paper n. 25

June 2015

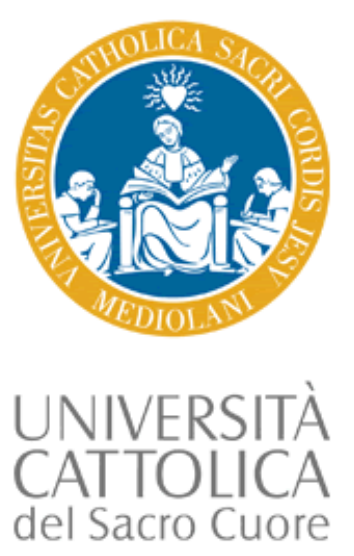




\title{
Deceptive Advertising with Rational Buyers
}

\section{Salvatore Piccolo, Piero Tedeschi, Giovanni Ursino}

Università Cattolica del Sacro Cuore

Working Paper n. 25

June 2015

\author{
Dipartimento di Economia e Finanza \\ Università Cattolica del Sacro Cuore \\ Largo Gemelli 1 - 20123 Milano - Italy \\ tel: +39.02.7234.2976 - fax: +39.02.7234.2781 \\ e-mail: dip.economiaefinanza@unicatt.it
}

The Working Paper Series promotes the circulation of research results produced by the members and affiliates of the Dipartimento di Economia e Finanza, with the aim of encouraging their dissemination and discussion. Results may be in a preliminary or advanced stage. The Dipartimento di Economia e Finanza is part of the Dipartimenti e Istituti di Scienze Economiche (DISCE) of the Università Cattolica del Sacro Cuore. 


\title{
Deceptive Advertising with Rational Buyers*
}

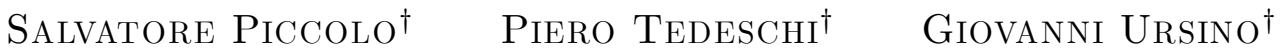

January 8, 2015

\begin{abstract}
We study a game in which two competing sellers supplying experience goods of different quality can induce a perspective buyer into a bad purchase through (costly) deceptive advertising. We characterize the equilibrium set of the game and argue that an important class of these outcomes features pooling behavior at the pricing stage while requiring low quality sellers to air false claims about their product. These claims deceive the buyer and induce a bad purchase with positive probability. Although the low-quality product is purchased with positive probability in these equilibria, the buyer's (expected) utility can be higher than in a fully separating equilibrium. This result suggests that, surprisingly, deceptive practices may actually enhance competition. Finally, we characterize the optimal deterrence by a regulatory agency that seeks to punish deceptive practices. We show that consumer surplus maximization requires lower deterrence than social welfare maximization. The analysis is robust to various extensions.
\end{abstract}

JEL Classification Numbers: L13, L15, L4

Keywords: Asymmetric Information, Bayesian Consumers, Deception, Misleading Advertising, Signaling.

\footnotetext{
${ }^{*}$ For valuable comments and discussions we would like to thank also Ermelinda Ciaralli, Ferdinando Colombo, Vincenzo Denicolò, Andrea Galeotti, Dino Gerardi, Michele Grillo, Jakub Kastl, Jeanine Miklós-Thal, Emanuele Tarantino, Chris Wallace as well as seminar participants at the Università Cattolica del Sacro Cuore of Milan, Scuola Sant'Anna of Pisa, the University of Essex, the University of Leicester, EEA|ESEM 2013 and EARIE 2013. Errors are ours. Corresponding author: Salvatore Piccolo, Tel. +390272342981; email: salvapiccolo@gmail.com

${ }^{\dagger}$ Department of Economics and Finance, Università Cattolica del Sacro Cuore, Milan.
} 


\section{Introduction}

When the quality of an item on sale can be verified before purchase (the so called search goods), firms' advertising activities are unlikely to harm consumers insofar as they allow to save on search costs and induce a better match between tastes and consumption choices — see, e.g., Lewis and Sappington (1994) and Johnson and Myatt (2006) among others. Very often, however, product quality is not fully verifiable before consumption - e.g., experience goods. In these cases advertising may have a dark side: low-quality firms can use marketing channels to induce consumers into bad purchases.

These practices are known as misleading or deceptive advertising, which is defined as any explicit (or even implicit) statement that has the potential to deceive consumers, meaning that its embedded claim may not realize after the purchase - see, e.g., Wilson (2000). This potential danger has been well recognized by antitrust and competition policy authorities all over the world. ${ }^{1}$ When firms engage in deceptive advertising, the civil law principle stating that customers have a 'right to know' what they are purchasing is likely to be violated. Policy makers have also grown wary of potential market distortions of deceptive practices as they tend to induce unfair competition. As a result, misleading advertising is generally sanctioned according to country-specific regulations designed to protect consumers and foster competition. Surprisingly, the existing literature has not devoted enough attention to these issues.

The analysis proposed in this paper is a contribution to this debate. The research questions that we address are the following: Why do firms engage in deceptive advertising? What are the cost-benefit trade-offs that shape misleading advertising decisions? When is it more likely that deceptive conducts emerge in practice? Do these practices really enhance competition? What is their effect on consumers?

To address these issues, we consider a simple game in which two sellers (firms) compete by setting prices to attract a representative buyer (consumer). Sellers produce vertically differentiated goods whose quality is unknown to the buyer before consumption (experience goods) and cannot be assessed with certainty in courts. Qualities are perfectly negatively correlated - one is high, one is low - and a lowquality seller may choose to deceive the buyer so as to induce him into a bad purchase. A seller deceives the buyer if the latter buys from the former a product of low quality that was (falsely) advertised as a high-quality good. When a seller invests in advertising, she airs a message about the quality of her product that reaches the buyer with a probability that is increasing with the total amount of the seller's expenditures in advertising. These expenditures are not observable by the buyer, but it is commonly known that advertising is more costly for the low-quality seller. ${ }^{2}$ The buyer knows that one of the sellers supplies a low-quality good and uses all the available information to make inference about the quality of the items on sale, so as to minimize the danger of a bad purchase.

Our equilibrium characterization offers a novel rationale for deceptive advertising in a competitive setting and delivers relevant policy implications. In particular, we establish conditions under which low-quality sellers engage in deceptive advertising. We show that, even when the game features multiple

\footnotetext{
${ }^{1}$ See, e.g., the US FTC Policy Statement Regarding Advertising Substantiation.

${ }^{2}$ For example, this reflects the chances of incurring sanctions of customer protection agencies and/or competition authorities.
} 
equilibria, deception emerges in many plausible circumstances. Finally, we study how this affects the buyer's welfare. Interestingly, the buyer may prefer (pooling) outcomes in which both types of sellers charge equal prices, engage in advertising and the buyer is deceived with some (endogenous) probability to (separating) outcomes in which sellers quote different prices and the buyer purchases the high-quality item with certainty. In fact, our model highlights a novel tension between transparency and competition: the buyer may prefer not to learn qualities through prices, but rather get an imperfect signal via the sellers' advertising even though this may induce a bad purchase. ${ }^{3}$

We start the analysis by noting that equilibria in which sellers advertise are incompatible with separating behavior at the pricing stage. In fact, in separating equilibria the information about qualities is fully revealed by prices and there is no scope for advertising. Thus, deceptive advertising can only emerge if sellers pool and charge equal prices. The first part of the analysis is devoted to characterize 'deceptive' equilibria in which both types of sellers advertise and the buyer is deceived with some probability. Whenever trade occurs, we show that deception emerges in equilibrium if and only if the quality differential between high- and low-quality items is large enough and engaging in deceptive advertising is not too costly. The price that can be sustained in equilibrium is not unique, but varies within a compact set. By the asymmetry of advertising costs, high-quality sellers always advertise more intensely than low-quality ones. Such a difference generates an increase in the buyer's willingness to pay for an item of uncertain characteristics since advertising becomes an informative signal of quality: we call this feature 'advertising premium'. Further, we show that, the larger the equilibrium price, the higher the investment in advertising of both sellers. If the advertising technology displays learning-by-doing, the advertising premium increase with the equilibrium pooling price. This is because the difference between advertising intensities grows larger, allowing the buyer to make a sharper inference out of the signals he observes. Interestingly, we show that, if this is the case and the qualities of the items on sale are different enough, the buyer may actually prefer (in expectation) not only equilibria with positive deception but also with relatively high prices - i.e., a price higher than the lowest deceptive equilibrium pooling price. In addition, we show that, when this result holds, the Pareto efficient equilibrium price of this class of outcomes exceeds its lowest value.

In the second part of the analysis we study no-deception outcomes of the game - i.e., equilibria that feature either no advertising at all (separating equilibria) or pooling at the pricing stage with advertising only by high-quality sellers. First, we find that the separating outcome is unique and emerges only when the quality differential between high- and low-quality items is large enough. In this equilibrium the high-quality seller serves the buyer at a price that makes him just indifferent between buying from her and purchasing the low-quality item at the competitive price. In fact, revelation of qualities through prices enables high-quality sellers to exploit a sort of monopoly power vis-à-vis the buyer — i.e., she

\footnotetext{
${ }^{3}$ Noteworthy, this prediction is very different from the findings of Heidhues, Köszegi, and Murooka (2012). Building on the "add-on" pricing approach proposed by Ellison (2005), they also analyze markets for deceptive products but in a context with naive consumers. In contrast to them, our deceptive equilibria may be pro-competitive vis-à-vis the corresponding no deception market outcome: in our model the possibility of deception allows low-quality sellers to stay on the market alongside high quality ones and this generates a downward pressure on prices.
} 
can extract from him the entire quality premium. As a result, the buyer may actually prefer to run the risk of being deceived and gather imperfect information about qualities through ads rather than learning them perfectly through prices. This is, again, the transparency-competition trade-off mentioned above.

Second, we show that the game always features pooling equilibria in which just the high-quality seller advertises her product, but her ads reach the buyer only with some probability (so that the low-quality seller may actually serve the customer in equilibrium). ${ }^{4}$ Again, a continuum of prices can be supported in equilibrium, but these are strictly lower than the prices which can be supported in a deceptive equilibrium.

The analysis suggests two normative conclusions. To discuss them, we introduce a regulatory authority which has the power to determine the additional costs of engaging in deceptive advertising e.g., by choosing the amount of effort put into investigating misleading conducts. First, we argue that an Authority concerned with buyer protection may not support a complete shut down of the pooling equilibria involving deceptive advertising. The reason is that sellers might then coordinate on the separating outcome in which the buyer is worse-off, thereby suggesting that deceptive practices may actually enhance competition. To make this point clear, suppose that consumers prefer the pooling equilibrium with only truthful advertising to the pooling equilibrium with deceptive advertising, and the latter to the separating one. We construct an example in which, if the Authority is able to completely discourage sellers from deceiving the buyer — e.g., by making the cost of false statements excessively high — this induces sellers to coordinate on the even worst (for the buyer) separating outcome. Intuitively, this result is likely to occur when the quality differential between the sellers' products is large enough, so that the monopoly power awarded by the separating equilibrium to the high-quality seller causes to the buyer a higher loss than the expected damage from a bad purchase in a pooling outcome.

Second, we show that the policy that maximizes the buyer's expected utility is more lenient than the policy that maximizes total (expected) welfare - i.e., maximizing the buyer's expected surplus requires an expected sanction that is lower than the one that maximizes total welfare. This is because consumers do not internalize the cost saving effect of a reduction in wasteful advertising. Hence, our analysis suggests that deterrence against deceptive practices is likely to be stronger when it is delegated to antitrust authorities (e.g., USA) as opposed to customer protection agencies (e.g., Italy).

The analysis is concluded with two natural extensions of the baseline model. We show that the main qualitative insights of our contribution do not change if the sellers' types are not perfectly (negatively) correlated. Then, we characterize an additional class of pooling deceptive equilibria with 'market break down'. In these equilibria both sellers post a price that induces the buyer not to purchase when he observes ads from both sellers or no ads at all. The pooling prices supported by these equilibria are higher than those emerging when trade occurs with certainty. However, we also find sufficient conditions under which sellers prefer not to induce the market to break down and rather coordinate on deceptive equilibria in which trade occurs with certainty.

\footnotetext{
${ }^{4}$ This is what we will call 'partial coverage', which occurs when the marginal benefit of covering the entire market is smaller than the required penetration cost of advertising.
} 
Finally, it should be mentioned that, from a theoretical point of view, the game we analyze lies at the boundary between cheap talk and signaling games: it is not a pure signaling model since investments in advertising are not observed, yet it is not a pure cheap talk game because ads are indeed costly and costs are asymmetric. To the best of our knowledge, this class of games has received little attention in the existing literature. ${ }^{5}$ Hence, in addition to its normative insights, the analysis also offers a contribution to the theoretical literature that typically separates the approaches just mentioned.

The rest of the paper is organized as follows. Section 2 relates our work to the growing literature on deceptive practices. Section 3 lays down the baseline model. In Section 4 we argue why deceptive practices are not compatible with a separating outcome. Section 5 describes the properties of equilibria with positive deception, provides the main existence result and highlights some relevant comparative statics. In Section 6 we characterize equilibria without deceptive advertising. Section 7 proposes a criterion to select among equilibria and develops a welfare analysis. In Section 8 we show how policies that maximize the buyer's expected utility differ from those aimed at maximizing total welfare. Section 9 provides two natural extensions of the baseline model. Section 10 concludes. Proofs are in the Appendix.

\section{Related literature}

Our paper contributes to the literature dealing with deceptive practices — see, e.g., Bagwell (2007) among others. A seminal contribution to the debate is that of Anderson and Renault (2009) who study a model in which competing firms disclose horizontally differentiated attributes (valued differently by heterogeneous consumers), assuming that product qualities are known. ${ }^{6}$ In their paper, if comparative advertising is allowed, firms with a lower market share are more likely to disclose information about their products than larger firms. Although both papers share the idea of comparative claims, the key difference between our model and theirs is that we focus on deceptive practices while in their model information disclosure is always truthful.

Barigozzi, Garella, and Peitz (2009) study an entry game in which the entrant's quality is uncertain and comparative advertising - i.e., comparing quality of one's own product to that of a rival - empowers the latter to file for court intervention if she believes the comparison to be false or misleading. They show that comparative advertising can be a credible signal of high quality. In contrast to theirs, in our model there is no way to credibly signal high quality because firms cannot file for court intervention. Moreover, in our model the quality of both firms is unknown, while in their set up the incumbent quality is common knowledge. These differences allow us to analyze the welfare implications of deceptive advertising from a more symmetric angle relative to the entry perspective taken in their paper. Finally, while prices are never used as signaling devices in their paper, in our model buyers rely (also) on prices when updating their beliefs.

\footnotetext{
${ }^{5}$ One exception is Kotowitz and Mathewson (1979). However, differently from us, in their paper there is a single (monopolist) seller who might deceive customers via deceptive advertising.

${ }^{6}$ See also Anderson and Renault (2006) for a similar disclosure approach with a monopolistic firm.
} 
Hattori and Higashida (2012) study the welfare effects of persuasive advertising in a duopoly model in which horizontally differentiated firms that compete by setting prices, engage in deceptive advertising. They characterize the welfare effects of alternative forms of regulatory policies, by emphasizing (among other things) the positive effects of market interventions aimed at educating consumers. By contrast, our objective is to study a context in which customers are Bayes-rational and the scope for deceptive advertising has a direct impact on prices through the informative content of ads.

The work on de-marketing by Miklós-Thal and Zhang (2013) borrows attribution theory from psychology and builds a model in which sellers may prefer to under-advertise their high-quality product in equilibrium. By so doing, sellers 'confuse' potential buyers as to the true cause of possibly low sales, which may be attributed to the low-profile marketing choice (observed) rather than to the low quality of the item on sale (unobserved). Our work shares common features with Miklós-Thal and Zhang (2013) in that buyers are Bayes-rational and discount information in a similar fashion. However, a fundamental difference between our model and theirs regards the way advertising affects preferences: while in their analysis advertising increases demand by arousing potential buyers' curiosity - a reduced form of persuasive advertising - in our setting advertising persuades customers only through changes in probabilities leaving unaltered their attitude towards learning an item's quality — i.e., demand is enhanced only through subjective probability appraisal.

Of course, stemming from Chamberlin (1933) a large body of industrial organization literature has cast advertising choices within the traditional oligopoly framework — see, e.g., Bagwell (2007) for an excellent survey. These models highlight a number of important features of advertising strategies, such as their informative ${ }^{7}$ and persuasive ${ }^{8}$ role, the link between advertising and market structure ${ }^{9}$ and welfare properties. However, they are all rather silent on the potential danger of deceptive practices, which is the novel aspect emphasized in our analysis. ${ }^{10}$ The closest paper in this literature is Corts (2012). ${ }^{11}$ Differently from us, he emphasizes more the normative issues of deceptive practices: his analysis explores the differences between policies prohibiting false claims about product quality and policies requiring prior testing to substitute for quality claims. In his model sellers must invest in information gathering to learn their quality: there is costly signaling, which is not the case in our model since we assume that the buyer does not observe the sellers' advertising efforts. As a result, the most interesting outcomes of his game are the separating outcomes, whereas pooling equilibria are the focus of our work. In a companion paper, Piccolo, Tedeschi, and Ursino (2014b), we analyze a similar model in which firms may advertise deceptively, but they can do so only on the extensive margin - i.e., the claim about quality reaches

\footnotetext{
${ }^{7}$ See, e.g., Bagwell and Riordan (1991), Grossman and Shapiro (1984), Orzach, Overgaard, and Tauman (2002) and Wernerfelt (1994) for more on informative advertising.

${ }^{8}$ See, e.g., Banerjee and Bandyopadhyay (2003), Becker and Murphy (1993) and Dixit and Norman (1978).

${ }^{9}$ See, e.g., Bagwell and Ramey (1988), Bagwell and Ramey (1991), Chu (1992), Galeotti and Moraga-González (2008).

${ }^{10}$ An approach similar to ours is taken in Wang (2011) who studies, however, the problem of a monopolist that offers information about its product features - see also Kotowitz and Mathewson (1979). In this model advertising can be not fully informative but it cannot be misleading, which is instead a key feature of our analysis.

${ }^{11}$ See also Corts $(2013,2014,2015)$.
} 
the buyer with certainty. ${ }^{12}$ In the present paper advertising is treated in a more general form: it is a continuous variable, which is chosen on the intensive margin and therefore affects not only firms' pricing decision but also the consumer's expected utility in a non-obvious way. This allows us to show that the buyer may enjoy deceptive pooling equilibria in which sellers coordinate on the maximal price, whereas deception is good for the buyer only at the most competitive (minimum price) pooling equilibrium in our previous work. To the best of our knowledge this is the first paper in which deceptive advertising is determined also on the intensive margin.

\section{The model}

Players. Two competing sellers (denoted by $i=1,2$ ) supply similar products with different qualities to a single (representative) buyer. They compete by setting prices and each offers a product of either low or high quality. The buyer purchases one unit of product from either seller and is unaware of qualities before consumption. His utility from consuming an item of low (resp. high) quality is $\theta_{l}$ (resp. $\theta_{h}$ ), with $\Delta \equiv \theta_{h}-\theta_{l}>0$ being the quality differential.

The buyer's net utility from consumption is

$$
u\left(\theta_{i}, p_{i}\right)=\theta_{i}-p_{i}
$$

when buying at a price $p_{i}$ from seller $i$ an item whose quality yields utility $\theta_{i}$. No consumption entails zero utility. ${ }^{13}$ Abusing slightly notation, we define sellers' types as $\theta_{i} \in\left\{\theta_{l}, \theta_{h}\right\}$.

Uncertainty. For simplicity, in the baseline model we assume that qualities are perfectly negatively correlated - i.e., $\theta_{1}=\theta_{l}$ whenever $\theta_{2}=\theta_{h}$ and vice versa - and this is common knowledge to all players. ${ }^{14}$ Hence, each seller is aware of both own and the competitor's product quality, while the buyer knows that there is only one good-quality product but cannot tell which. One interpretation of this assumption is that product qualities can always be ranked and buyers may just care about the ranking rather than intrinsic quality: it is known in the market that some products are better than others, but the winner is not obvious outright. The sellers know which product is best out of their insider/specialist information, while the buyer only has a prior about that. Thus, $\theta_{h}$ captures the willingness to pay for the fanciest, top-quality product, while $\theta_{l}$ is the maximum a buyer is willing to pay for a laggard, low-quality product. ${ }^{15}$ Sellers are ex-ante identical from the buyer's perspective: his prior belief about

\footnotetext{
${ }^{12}$ This is sometimes referred to as 'perfect advertising' in the literature.

${ }^{13}$ The hypothesis of a single representative buyer is made only for tractability and to isolate the pure effects of deceptive advertising from those stemming from product segmentation that would arise with a downward sloping demand function. Our results would not change if there was a continuum of buyers and firms can perfectly discriminate among them. See, however, Grossman and Shapiro (1984) and Galeotti and Moraga-González (2008) for models with advertising, differentiated products and segmentation.

${ }^{14}$ In the extensions we show that the main results remain qualitatively valid when qualities are imperfectly correlated.

${ }^{15}$ Alternatively, our set-up can be interpreted as a shortcut to model situations in which sellers discretely improve the quality of their products. This innovation process takes place in discrete but small time intervals so that in each (market
} 
their qualities is $50-50$.

Advertising technology. Prices are observed before purchase, while product qualities are advertised through informative ads. Specifically, each seller can air a number of ads stating that her product is of high quality. The higher the number of ads, the larger the probability of reaching the buyer (hereafter coverage). ${ }^{16}$ If seller $i$ supplies a high-quality product, the statement of her ads is truthful and her coverage will be denoted by $t_{i} \in[0,1]$ - i.e., her ads reach the buyer with probability $t_{i} \leq 1$. If seller $i$ supplies a product of low quality, the content of her ads is false and her coverage will be denoted by $d_{i} \in[0,1]$ - i.e., her ads reach the buyer with probability $d_{i} \leq 1$. To simplify notation, throughout we will assume that the buyer receives a signal $s_{i}=h$ from seller $i$ when her ads reach the target, while he observes signal $s_{i}=\varnothing$ when the target is missed. Accordingly, we will denote by $\mathbf{s}=\left(s_{1}, s_{2}\right) \in\{h, \varnothing\}^{2}$ the vector of signals that the buyer observes.

The buyer cannot distinguish the quality of the items on sale before consumption - i.e., sellers supply experience goods. Moreover, quality cannot be verified ex-post in court with certainty. Advertising requires an increasing and convex penetration cost $c(\cdot)$, which satisfies standard Inada conditions - i.e., $c(0)=c^{\prime}(0)=0 .{ }^{17}$ A high-quality seller, who advertises truthfully, only sustains the penetration cost. By contrast, deceptive advertising costs $c\left(d_{i}\right)+\phi d_{i}$ to seller $i$ when she supplies the low-quality item (with $\phi>0$ ). The linear component $\phi$ can be interpreted as the expected sanction (fine) of deceiving consumers. ${ }^{18}$

Finally, we assume that $c^{\prime}(1)$ is arbitrarily large to rule out equilibria with full coverage - i.e., it will never be optimal for a seller to cover the entire market. ${ }^{19}$

Timing. The timing of the game is as follows:

$\mathrm{t}=0$ Sellers learn their qualities.

$\mathrm{t}=1$ Sellers simultaneously and independently choose coverage and price.

$\mathrm{t}=2$ The buyer receives ads (if any) and observes the posted prices (but not coverage decisions).

$\mathrm{t}=3$ He decides which store to patronize. Trade (if any) takes place.

Figure 1 below illustrates the time-line of the game.

game) stage only one seller improves upon the previous stage best quality product. Buyers know that in each period there is a status quo quality level, which is valued $\theta_{l}$, and that only one of the sellers innovated by selling a product of better quality, which is valued $\theta_{h}$.

${ }^{16}$ This is sometimes referred to as 'advertising rate' in the literature.

${ }^{17}$ This echoes the 'penetration' costs common in the advertising literature — see, e.g., Bagwell (2007). Essentially, even though buyers are aware of the existence of both sellers, coverage costs refer to the provision of additional information about quality-related characteristics of the goods needed to attract buyers.

${ }^{18}$ For example, one could imagine that every deceived customer sues the firm for fraud with some probability, suggesting that the costs in excess of mere coverage/penetration costs are linear.

${ }^{19}$ In a previous version of the paper we have performed an analysis of this game in which Inada conditions do not hold and a corner solution emerges with the high-quality seller covering the entire market. The paper is available on SSRN at: http://dx.doi.org/10.2139/ssrn.2172714 
Figure 1: Timing of the Advertising Game

\begin{tabular}{|c|c|c|c|}
\hline $\begin{array}{c}\text { Qualities } \\
\text { are revealed } \\
\text { to sellers }\end{array}$ & $\begin{array}{c}\text { Sellers simultaneously } \\
\left.\text { set } t_{1} \text { (or } d_{1}\right) \text { and } p_{1} \\
\left.\text { and } d_{2} \text { (or } t_{2}\right) \text { and } p_{2}\end{array} \longrightarrow \begin{array}{c}\text { Buyer observes ads } \\
\text { and prices, and may } \\
\text { buy from either seller }\end{array}$ \\
\hline
\end{tabular}

Time 0

Time 1

Time 2 and 3

A final comment on the structure of our model is in order: advertising is about quality and does not concern existence. The buyer is perfectly aware of the existence of both sellers ${ }^{20}$ even if he is not reached by their ads. This hypothesis can be interpreted in two different ways. First, even if they know about the existence of established competitors, customers are usually unable to observe the firms' actual investments in advertising campaigns. Second, our model can be reinterpreted as the buyer having the ability to distinguish only whether a firm has pursued an intense or a soft advertising campaign but not its exact scale. ${ }^{21}$

Equilibrium concept and strategies. Since the game is sequential and features asymmetric information, the equilibrium concept is weak Perfect Bayesian Equilibrium (see, e.g., Mas-Colell, Whinston, and Green (1995)). Let $\left(t_{i}, d_{i}, p_{i}\right)$ be seller $i$ 's vector of actions where $t_{i} \in[0,1]$ and $d_{i} \in[0,1]$ are, respectively, her truthful and deceptive ads coverage, ${ }^{22}$ and $p_{i}$ the posted price. The buyer's action space is $\{$ buy 1 , buy 2, not buy $\}$. For simplicity, in the baseline model we focus on equilibria in which trade occurs with certainty - i.e., the market never breaks down — and denote by

$$
\left.\alpha_{i}(\mathbf{s}, \mathbf{p})=\operatorname{Pr}(\text { buy } i \mid \mathbf{s}, \mathbf{p})=1-\operatorname{Pr}(\text { buy } j \mid \mathbf{s}, \mathbf{p})\right)
$$

the buyer's 'consumption' strategy. This is conditional both on the observed ads s and on the vector of posted prices $\mathbf{p}=\left(p_{i}, p_{j}\right)$. Equilibria with market breakdown will be discussed in the extensions.

Beliefs. At Time 2, the buyer observes the posted prices and at most one ad from each seller. Using this information he updates his beliefs on products' qualities consistently (whenever possible) with equilibrium strategies. We will introduce off-equilibrium beliefs as we proceed with the analysis.

\footnotetext{
${ }^{20}$ This assumption seems compelling for an oligopolistic industry with a small number of established competitors in which buyers make consumption decisions about new types or versions of existing products - e.g., car models, electronic devices etc. One might argue that consumers are aware of the existence of firms, but not necessarily of the new versions of their products. However, when search costs are small enough, knowledge about the existence of brands also implies awareness of product versions.

${ }^{21}$ In this case, the buyer perceives seller $i$ 's advertising campaign as intense when $s_{i}=h$, and soft if $s_{i}=\varnothing$.

${ }^{22}$ These are, in fact, pure behavior strategies: conditional on being a high type, seller $i$ 's strategy is $t_{i}$, otherwise $d_{i}$.
} 


\section{Preliminaries}

In this preliminary section we describe how sellers' advertising and pricing choices affect the buyer's behavior. We show that the low-quality seller has no incentive to invest in deceptive advertising when prices are a perfect signal of quality - i.e., in a separating equilibrium in which sellers of different types charge different prices.

For any pair of signals $\left(s_{i}, s_{j}\right)$ and any vector of prices $\left(p_{i}, p_{j}\right)$, the buyer will patronize seller $i$ (resp. $j$ ) with probability 1 if and only if his expected utility when buying from seller $i$ is (strictly) higher than the expected utility he obtains buying from seller $j$ - i.e.,

$$
\begin{aligned}
\sum_{\theta_{i}} \operatorname{Pr}\left(\theta_{i} \mid \mathbf{s}, \mathbf{p}\right) \theta_{i}-p_{i} & >\sum_{\theta_{i}} \operatorname{Pr}\left(\theta_{j} \mid \mathbf{s}, \mathbf{p}\right) \theta_{j}-p_{j} \quad(\text { resp. } \quad<) \Rightarrow \\
\alpha_{i}(\mathbf{s}, \mathbf{p}) & =1 \quad\left(\operatorname{resp} . \alpha_{i}(\mathbf{s}, \mathbf{p})=0\right),
\end{aligned}
$$

where $\operatorname{Pr}\left(\theta_{i} \mid \mathbf{s}, \mathbf{p}\right)$ is the posterior (conditional both on signals and prices) induced by the sellers' strategies - i.e., the probability that the buyer assigns to seller $i$ being of quality $\theta_{i} \in\left\{\theta_{l}, \theta_{h}\right\}$ when he has observed signals $\mathbf{s}=\left(s_{i}, s_{j}\right)$ and prices $\mathbf{p}=\left(p_{i}, p_{j}\right)$. When indifferent, the buyer randomizes and patronizes seller $i$ with probability $\alpha_{i}(\cdot) \in(0,1)$.

Given the buyer's strategy, seller $i$ 's maximization problem when she supplies a high-quality item is

$$
\max _{p_{i} \geq 0, t_{i} \in[0,1]}\left\{\sum_{\mathbf{s} \in\{h, \varnothing\}^{2}} \operatorname{Pr}\left(\mathbf{s} \mid t_{i}, d_{i}\right) \alpha_{i}(\mathbf{s}, \mathbf{p}) p_{i}-c\left(t_{i}\right)\right\} .
$$

When, instead, she supplies a low-quality item, her maximization problem is

$$
\max _{p_{i} \geq 0, d_{i} \in[0,1]}\left\{\sum_{\mathbf{s} \in\{h, \varnothing\}^{2}} \operatorname{Pr}\left(\mathbf{s} \mid t_{i}, d_{i}\right) \alpha_{i}(\mathbf{s}, \mathbf{p}) p_{i}-c\left(d_{i}\right)-\phi d_{i}\right\} .
$$

The following preliminary lemma shows that there is no advertising in a separating equilibrium. This result is key to understand how the incentives to deceive the buyer are affected by the seller's pricing behavior:

Lemma 1. A separating equilibrium in which prices fully reveal qualities - i.e., such that sellers of different qualities post different prices - features no advertising.

The economic intuition of this result is straightforward. In a separating equilibrium sellers perfectly reveal their quality through prices. Hence, there is no scope for costly advertising. As a result, advertising can only emerge in a pooling equilibrium in which sellers charge the same price regardless of their qualities - i.e., in an outcome of the game in which prices do not convey information about quality. 


\section{$5 \quad$ Pooling equilibria with deceptive advertising}

Building on Lemma 1, in this section we analyze the class of pooling equilibria in which the buyer is deceived with positive probability. Throughout the analysis we restrict attention to symmetric (labelsinvariant) equilibria in which trade occurs with certainty. Specifically, in these equilibria: $(i)$ both sellers post the same price (say $p^{*}$ ) regardless of their quality; $(i i)$ high-quality sellers invest $t^{*} \in(0,1)$ in truthful advertising $\left(t_{i}^{*}=t^{*}\right.$ for every $i$ ); (iii) low-quality sellers invest $d^{*} \in[0,1)$ in deceptive advertising $\left(d_{i}^{*}=d^{*}\right.$ for every $\left.i\right) ;(i v)$ the buyer's participation constraint is always met.

The section is structured as follows. We first specify the buyer's beliefs off- and on-equilibrium path; we derive some basic properties of the equilibrium strategies; finally, we provide the necessary and sufficient conditions for existence.

In the equilibrium candidate under consideration both sellers advertise. As a result, the buyer cannot spot deviations upon observing or not observing an ad from any of the sellers. By contrast, he learns to be off-equilibrium when he observes unexpected prices. We assume the following off-equilibrium beliefs:

A1 Whenever sellers are expected to post the same price in equilibrium, if the buyer observes a nonequilibrium price from just one seller, he believes she sells a low-quality product, for any ads he may observe. Similarly, when he observes two non-equilibrium prices, he assigns probability 1 of selling a low-quality product to the seller posting the lower price, for any ads he may observe.

These beliefs are standard in applications of signaling games. At the end of the section we show that the equilibrium outcome characterized throughout survives to the weakest version of Divinity (D1) introduced by Banks and Sobel (1987).

Next, we characterize beliefs on the equilibrium path. Using Bayes' rule, the buyer's equilibrium beliefs (posterior) on firm $i$ 's quality being high when he receives only one ad are

$$
\begin{aligned}
& \operatorname{Pr}\left(\theta_{i}=\theta_{h} \mid h, \varnothing, \mathbf{p}^{*}\right)=\frac{t^{*}\left(1-d^{*}\right)}{t^{*}\left(1-d^{*}\right)+\left(1-t^{*}\right) d^{*}}, \\
& \operatorname{Pr}\left(\theta_{i}=\theta_{h} \mid \varnothing, h, \mathbf{p}^{*}\right)=\frac{\left(1-t^{*}\right) d^{*}}{t^{*}\left(1-d^{*}\right)+\left(1-t^{*}\right) d^{*}},
\end{aligned}
$$

where $\mathbf{p}^{*}=\left(p^{*}, p^{*}\right),\left(s_{i}, s_{j}\right)=(h, \varnothing)$ in $(1)$ and the reverse in $(2)$. Notice that

$$
\frac{\partial \operatorname{Pr}\left(\theta_{i}=\theta_{h} \mid h, \varnothing, \mathbf{p}^{*}\right)}{\partial t^{*}}>0, \quad \frac{\partial \operatorname{Pr}\left(\theta_{i}=\theta_{h} \mid h, \varnothing, \mathbf{p}^{*}\right)}{\partial d^{*}}<0
$$

and

$$
\frac{\partial \operatorname{Pr}\left(\theta_{i}=\theta_{h} \mid \varnothing, h, \mathbf{p}^{*}\right)}{\partial t^{*}}<0, \quad \frac{\partial \operatorname{Pr}\left(\theta_{i}=\theta_{h} \mid \varnothing, h, \mathbf{p}^{*}\right)}{\partial d^{*}}>0 .
$$

Essentially, an increase of the intensity of truthful (resp. deceptive) advertising makes the buyer more (resp. less) confident that the high quality seller is the one from which he has received an ad. 
By contrast, when the buyer receives the same signal from both sellers, his posterior is equal to the prior - i.e.,

$$
\begin{gathered}
\operatorname{Pr}\left(\theta_{i}=\theta_{h} \mid h, h, \mathbf{p}^{*}\right)=\operatorname{Pr}\left(\theta_{j}=\theta_{h} \mid h, h, \mathbf{p}^{*}\right)=\frac{1}{2}, \\
\operatorname{Pr}\left(\theta_{i}=\theta_{h} \mid \varnothing, \varnothing, \mathbf{p}^{*}\right)=\operatorname{Pr}\left(\theta_{j}=\theta_{h} \mid \varnothing, \varnothing, \mathbf{p}^{*}\right)=\frac{1}{2} .
\end{gathered}
$$

We are now ready to characterize the buyer's equilibrium strategy in a symmetric pooling equilibrium. Recall that, for any vector of signals $\mathbf{s} \in\{h, \varnothing\}^{2}$, the buyer's (equilibrium) strategy (when both sellers charge the same price) specifies a probability $\alpha_{i}^{*}(\mathbf{s})$ of buying from seller $i$ upon observing the pair of signals $\mathbf{s .}^{23}$

Lemma 2. In every symmetric pooling equilibrium in which trade occurs with certainty, the buyer's strategy must satisfy the following properties: $(i)$ symmetry - i.e., $\alpha_{i}^{*}\left(s, s^{\prime}\right)=\alpha_{j}^{*}\left(s, s^{\prime}\right)$ for every $\left(s, s^{\prime}\right)$; (ii) when the buyer receives only one ad, he patronizes the seller who has aired that ad - i.e., $\alpha_{i}^{*}(h, \varnothing)=$ 1 (resp. 0) - if and only if $t^{*}>d^{*}$ (resp. <); (iii) when the buyer receives two identical signals, he patronizes both sellers with equal probability - i.e., $\alpha_{i}^{*}(s, s)=1 / 2$.

Intuitively, since sellers are ex-ante identical, a symmetric equilibrium exists if and only if the buyer treats them symmetrically at the interim stage. That is, if the buyer is indifferent between purchasing from either seller (because he has not received decisive information from their ads) he behaves according to his 50-50 prior. Hence, provided he expects a positive utility, he purchases from either seller with identical probability.

Finally, a direct implication of Lemma 2 is that

$$
\operatorname{Pr}\left(\theta_{i}=\theta_{h} \mid h, \varnothing, \mathbf{p}^{*}\right)>\operatorname{Pr}\left(\theta_{i}=\theta_{h} \mid \varnothing, h, \mathbf{p}^{*}\right) \quad \Leftrightarrow \quad t^{*}>d^{*}
$$

Meaning that, when the buyer receives only one ad, he buys from the firm that has aired this ad only if (in equilibrium) the high-quality seller invests more in advertising than the low-quality one.

Notice also that, in the natural case in which $t^{*}>d^{*}$, then

$$
\begin{aligned}
\mathrm{E}\left[\theta_{i} \mid s_{i}=h, s_{j}=\varnothing, \mathbf{p}^{*}\right] & =\theta_{l}+\frac{t^{*}\left(1-d^{*}\right)}{t^{*}\left(1-d^{*}\right)+(1-t) d^{*}} \Delta \\
& >\mathrm{E}\left[\theta_{j} \mid s_{j}=\varnothing, s_{i}=h, \mathbf{p}^{*}\right]=\theta_{l}+\frac{\left(1-t^{*}\right) d^{*}}{t^{*}\left(1-d^{*}\right)+\left(1-t^{*}\right) d^{*}} \Delta,
\end{aligned}
$$

and

$$
\mathrm{E}\left[\theta_{i} \mid h, h, \mathbf{p}^{*}\right]=\mathrm{E}\left[\theta_{i} \mid \varnothing, \varnothing, \mathbf{p}^{*}\right]=\mathrm{E}\left[\theta_{i}\right]=\theta_{l}+\frac{\Delta}{2}
$$

\footnotetext{
${ }^{23}$ Abusing slightly notation we have suppressed the dependence of the buyer's strategy from the price since in any pooling equilibrium both sellers post the same price.
} 
Therefore, it can be easily shown that

$$
\mathrm{E}\left[\theta_{i} \mid s_{i}=h, s_{j}=\varnothing, \mathbf{p}^{*}\right]>\mathrm{E}\left[\theta_{i} \mid h, h, \mathbf{p}^{*}\right]=\mathrm{E}\left[\theta_{i} \mid \varnothing, \varnothing, \mathbf{p}^{*}\right]
$$

This implies that, to ensure trade in all states of nature, the equilibrium price $p^{*}$ must be fall short of the unconditional expected quality $\mathrm{E}\left[\theta_{i}\right]$.

Next, consider the sellers' equilibrium strategies. For any pair $(t, d)$, let $Q_{i}\left(t_{i}=t, d_{j}=d \mid h\right)$ be the ex-ante probability of making a sale for seller $i$ when she supplies a high-quality item - i.e.,

$$
\begin{aligned}
Q_{i}\left(t_{i}=t, d_{j}=d \mid h\right) & \equiv \sum_{\mathbf{s} \in\{h, \varnothing\}^{2}} \operatorname{Pr}(\mathbf{s} \mid t, d) \alpha_{i}^{*}(\mathbf{s}) \\
& =\frac{t d}{2}+t(1-d) \alpha_{i}^{*}(h, \varnothing)+d(1-t) \alpha_{i}^{*}(\varnothing, h)+\frac{(1-t)(1-d)}{2} .
\end{aligned}
$$

By the same token, let $Q_{i}\left(d_{i}=d, t_{j}=t \mid l\right)$ be the ex-ante probability of making a sale for seller $i$ when she supplies a low-quality item - i.e.,

$$
\begin{aligned}
Q_{i}\left(d_{i}=d, t_{j}=t \mid l\right) & \equiv \sum_{\mathbf{s} \in\{h, \varnothing\}^{2}} \operatorname{Pr}(\mathbf{s} \mid t, d) \alpha_{i}^{*}(\mathbf{s}) \\
& =\frac{t d}{2}+d(1-t) \alpha_{i}^{*}(h, \varnothing)+t(1-d) \alpha_{i}^{*}(\varnothing, h)+\frac{(1-t)(1-d)}{2}
\end{aligned}
$$

Hence, given an equilibrium pooling price $p^{*}$, high-quality sellers choose an equilibrium intensity of truthful advertising that solves

$$
\max _{t \in[0,1]}\left\{p^{*} Q_{i}\left(t_{i}=t, d_{j}=d^{*} \mid h\right)-c\left(t_{i}\right)\right\}
$$

whose first-order condition yields

$$
p^{*}\left[d^{*}-\frac{1}{2}+\left(1-d^{*}\right) \alpha_{i}^{*}(h, \varnothing)-d^{*} \alpha_{i}^{*}(\varnothing, h)\right]=c^{\prime}\left(t^{*}\right),
$$

Similarly, when supplying low quality, seller $i$ chooses an intensity of deceptive advertising that solves

$$
\max _{d \in[0,1]}\left\{p^{*} Q_{i}\left(d_{i}=d, t_{j}=t^{*} \mid l\right)-c(d)-\phi d\right\}
$$

whose first-order condition yields

$$
p^{*}\left[t^{*}-\frac{1}{2}+\left(1-t^{*}\right) \alpha_{i}^{*}(h, \varnothing)-t^{*} \alpha_{i}^{*}(\varnothing, h)\right]=c^{\prime}\left(d^{*}\right)+\phi
$$

Notice that, if $t^{*}>d^{*}$ so that $\alpha_{i}^{*}(h, \varnothing)=1$ and $\alpha_{i}^{*}(\varnothing, h)=0$, the left-hand sides of conditions $(5)$ and (6) (the sellers' marginal revenues) are both equal to $p^{*} / 2$ - i.e., each seller's serves the buyer $50 \%$ of 
the times regardless of her quality. Hence, the main difference between (5) and (6) is that the intensity of deceptive advertising involves the extra marginal cost $\phi$ over and above the penetration $\operatorname{cost} c(\cdot)$.

Lemma 3. Suppose that a symmetric pooling equilibrium exists in which both sellers charge the same price $p^{*}$, the low-quality seller invests $d^{*} \geq 0$ in deceptive advertising, the high-quality seller invests $t^{*}>0$ in truthful advertising and the market never breaks down. Then, the following properties are satisfied: (i) $p^{*} \geq 2 \phi ;($ ii $) 1>t^{*}>d^{*}$ so that $t^{*}$ and $d^{*}$ solve, respectively:

$$
\frac{p^{*}}{2}=c^{\prime}\left(t^{*}\right), \quad \frac{p^{*}}{2}=c^{\prime}\left(d^{*}\right)+\phi,
$$

where $d^{*} \geq 0$ with equality only at $p^{*}=2 \phi$. (iii) $t^{*}$ and $d^{*}$ are both increasing in $p^{*}$ while $d^{*}$ is decreasing in $\phi ;(i v)$ the high-quality seller earns more than the low-quality seller; and $(v) p^{*} \leq \mathrm{E}[\theta]=\theta_{l}+\frac{\Delta}{2}$.

The economic intuition of this result is as follows. Clearly, whenever the game features a (symmetric) pooling equilibrium in which the low-quality seller invests in deceptive advertising, it must be the case that the (equilibrium) marginal revenue $p^{*} / 2$ exceeds the marginal cost of deception $\phi$, so that the equilibrium price must be strictly above $2 \phi$. Moreover, since truthful advertising is less costly than deceptive advertising, it must be the case that the intensity of truthful advertising is larger than the intensity of deceptive advertising. This, in turn, implies that high-quality sellers earn higher profits than low-quality sellers. Finally, notice that, while at $p^{*}=2 \phi$ the low-quality seller does not invest in advertising (i.e. $d^{*}=0$ ), for easiness of exposition we will include price $2 \phi$ in the set of pooling equilibria with deception.

Building on Lemmas 2 and 3 we now characterize the sellers' incentive compatibility and participation constraints that must be satisfied in equilibrium. Recall that, by Lemma 3, the expected equilibrium profit of the high-quality seller is always larger than that of the low-quality seller. Hence, sellers' equilibrium profits are non-negative as long as the participation constraint of the low-quality seller is met - i.e.,

$$
\pi_{l}^{*} \equiv p^{*} \frac{1-t^{*}+d^{*}}{2}-c\left(d^{*}\right)-\phi d^{*} \geq 0
$$

Next, consider the sellers' no deviation constraints. Recall that advertising choices are not observable by the buyer and, by assumption A1, a seller who deviates is deemed as a low-quality one. Hence, she will rationally choose not to advertise when charging a deviation price $p^{\prime} \neq p^{*}$.

Consider a seller $i$ of either quality: she will never deviate to a price $p^{\prime}$ larger than $p^{*}$. In that case, the buyer would certainly buy from the rival because, under $\mathbf{A} \mathbf{1}$, the deviating firm is perceived as selling a low-quality item at a higher price. Hence, any feasible deviation must be such that $p^{\prime}<p^{*}$. Specifically, a deviating seller must price below $p^{*}-\Delta$ to compensate the buyer for the lower (perceived) quality. Regardless of her quality, the most profitable deviation of seller $i$ is to stop advertising (unobserved) and charge $p^{\prime}=p^{*}-\Delta$ (observed). Such a deviation yields a profit $p^{\prime}-\Delta$. Hence, pooling prices $p^{*}<\Delta$ can never be undercut since successful deviations yield negative profits. It thus remains to be verified whether pooling prices strictly larger than $\Delta$ are also immune to deviations. 
We have just argued that deviation profits are equal across sellers' types, and we know by Lemma 3 that the equilibrium profits of the high-quality seller always exceed those of the low-quality seller. Hence, a pooling price that prevents a deviation by the low-quality seller, a fortiori prevents that of a highquality seller. As a consequence, from now on we can restrict the analysis to the incentive compatibility constraint of the low-quality seller. This, together with her participation constraint, reads

$$
\pi_{l}^{*} \geq \max \left\{0, p^{*}-\Delta\right\}
$$

We can now state the main proposition of the section. Recalling that the equilibrium intensity of truthful $\left(t^{*}\right)$ and deceptive $\left(d^{*}\right)$ advertising depend on the equilibrium price $p^{*}$ as described in Lemma 3 :

Proposition 1. A (symmetric) weak PBE with the properties described in Lemma 2 and Lemma 3 exists if and only if

$$
\Delta \geq \Delta\left(\phi, \theta_{l}\right) \equiv \max \left\{\phi\left(1+c^{\prime-1}(\phi)\right), 2\left(2 \phi-\theta_{l}\right)\right\},
$$

where $\underline{\Delta}^{*}\left(\phi, \theta_{l}\right)$ is strictly increasing in $\phi$ and weakly decreasing in $\theta_{l}$. The maximal price that sellers can charge in this class of equilibria is

$$
\bar{p}^{*}=\min \{p(\phi, \Delta), \mathrm{E}[\theta]\},
$$

where $p(\phi, \Delta)$ is the unique solution to

$$
\frac{p^{*}}{2}\left[1-t^{*}+d^{*}\right]-c\left(d^{*}\right)-\phi d^{*}=p^{*}-\Delta .
$$

This result echoes the findings of Martimort and Moreira (2010) showing that common agency games with informed principals may feature pooling equilibria in which the informed principals offer the same allocations regardless of their types - i.e., what they call uninformative equilibria.

Condition (8) implies that a pooling equilibrium in which the low-quality seller deceives the buyer exists if and only if the quality differential is not too small. The reason is that, if $\Delta$ is too small, the low-quality seller always gains from revealing herself to the buyer by undercutting the equilibrium price and not advertising at all. To prevent this, it must be $\Delta>\phi\left(1+c^{\prime-1}(\phi)\right)$. Moreover, to induce the buyer to purchase even when he receives two identical ads, the expected quality $\mathrm{E}[\theta]$ must be larger than the minimum price. The latter is the price which allows for deceptive advertising to be positive $(2 \phi)$. Hence, to guarantee $\mathrm{E}[\theta]>2 \phi$, it must be that $\Delta>2\left(2 \phi-\theta_{l}\right)$.

Finally, it is easy to verify that the threshold $\triangleq\left(\phi, \theta_{l}\right)$ is increasing in $\phi$ : when the expected sanction of engaging in deceptive advertising increases, the region of parameters in which a pooling equilibrium exists shrinks.

The next corollary shows how the maximal pooling price $\bar{p}^{*}$ varies with $\Delta, \phi$ and $\mathrm{E}[\theta]$.

Corollary 1. $\bar{p}^{*}$ is weakly increasing in $\mathrm{E}[\theta]$, strictly increasing in $\Delta$, and weakly decreasing in $\phi$. 
The economic intuition is as follows. Clearly, when the maximal price is constrained by the buyer's participation constraint - i.e. $\bar{p}^{*}=\mathrm{E}[\theta]$ — the higher the expected quality the softer the constraint and the higher the price which can be sustained in equilibrium. As for the effect of $\phi$, notice that $\partial \pi_{l}^{*} / \partial \phi=-d^{*}$, so the equilibrium profit of the low-quality seller is decreasing in $\phi$. The deviation profit, however, is not affected by $\phi$. This implies that the participation and the incentive compatibility constraints of the sellers become tighter and, for relatively high prices, the incentives to deviate become too strong so that they cannot be sustained in equilibrium. Finally, when $\Delta$ increases, while equilibrium profits are unchanged, deviation profits decrease because the quality discount required by the buyer off-equilibrium is larger. Hence, deviations become harder, so that higher prices can be sustained in equilibrium when $\Delta$ grows large.

A remark on equilibrium refinements. We conclude the section by arguing that the equilibrium outcomes sustained by the off-equilibrium beliefs specified in A1 and characterized in Proposition 1 survive to the weakest version of Divinity (D1) introduced by Banks and Sobel (1987) — see, e.g., Fudenberg and Tirole (1991). ${ }^{24}$ In words, D1 states that if the set of the buyer's strategies that make seller $i$ of type $\theta$ willing to deviate to a given price $p^{d} \neq p^{*}$ is strictly contained in the set of the buyer's strategy that makes seller $i$ of type $\theta^{\prime}$ willing to deviate, then the buyer should believe that seller $i$ is infinitely more likely to deviate to $p^{d}$ when she is of type $\theta^{\prime}$ than when she is of type $\theta$.

To verify whether the pooling equilibria characterized survive to D1, consider a price deviation $p^{d} \neq p^{*}$, and assume that the buyer's off-equilibrium strategy is to buy from the deviating seller with some probability $\alpha .{ }^{25}$ The equilibrium price $p^{*}$ satisfies D1 if and only if $\alpha^{l}<\alpha^{h}$, where $\alpha^{h}$ is the buyer's off-equilibrium strategy that makes a seller indifferent between deviating and sticking to the equilibrium price when she is of high quality - i.e.,

$$
\alpha^{h} p^{d}=p^{*} \frac{1+t^{*}-d^{*}}{2}-c\left(t^{*}\right)
$$

By the same token, $\alpha^{l}$ is the buyer's strategy that makes a seller indifferent between deviating and sticking to the equilibrium price when she is of low quality - i.e.,

$$
\alpha^{l} p^{d}=p^{*} \frac{1-t^{*}+d^{*}}{2}-c\left(d^{*}\right)-\phi d^{*}
$$

It can be easily verified that, by Lemma $3, \alpha^{h}>\alpha^{l}$ regardless of $p^{*}$ so that, whenever a high-quality seller gains from deviation, the low-quality one does so too. Hence, all pooling equilibria characterized above meet D1. Essentially, for any given off-equilibrium behavior of the buyer, a high-quality seller has less incentives to deviate than a low-quality one because his equilibrium profits are higher.

\footnotetext{
${ }^{24}$ Of course, if our equilibria satisfy D1 they also satisfy the Cho and Kreps (1987) Intuitive Criterion.

${ }^{25}$ For simplicity, we assumed that the buyer's off-equilibrium strategy is unconditioned to the realized ads. It can be verified that D1 holds even if one considers a buyer's strategy that is contingent on the ads he obverses off-equilibrium.
} 


\subsection{Comparative statics}

In this section we study how the buyer's expected utility and the sellers' profits vary with the equilibrium price $p^{*}$. The objective is twofold. First, we show that, within the class of pooling equilibria with deceptive advertising, the buyer may be better-off when sellers coordinate on equilibrium prices strictly larger than $2 \phi$ - i.e., the buyer may benefit from being deceived with positive probability. Second, we provide sufficient conditions for establishing a ranking between sellers' profits, a rather complex task as we will argue.

Consider first the buyer's expected utility. Since in our model the buyer consumes only one unit of product, his (expected) utility, conditional on observing the same message from both sellers, is

$$
v(h, h)=v(\varnothing, \varnothing)=\mathrm{E}[\theta]-p^{*} .
$$

In this case, the buyer perceives both sellers equally likely to supply the high-quality item. Hence, his willingness to pay is the (unconditional) expected quality $\mathrm{E}[\theta]$.

By contrast, when the buyer observes a single message, he purchases from the seller whose ad he has observed. In this case, his beliefs are updated through Bayes' rule, so that

$$
v(h, \varnothing)=v(\varnothing, h)=\mathrm{E}[\theta \mid \varnothing, h]-p^{*}
$$

where

$$
\mathrm{E}[\theta \mid \varnothing, h]=\frac{t^{*}\left(1-d^{*}\right)}{t^{*}\left(1-d^{*}\right)+\left(1-t^{*}\right) d^{*}} \theta_{h}+\frac{\left(1-t^{*}\right) d^{*}}{t^{*}\left(1-d^{*}\right)+\left(1-t^{*}\right) d^{*}} \theta_{l} .
$$

Putting (9) and (10) together, the (unconditional) expected utility of the buyer before receiving the sellers' ads as a function of the equilibrium price $p^{*}$ is

$$
V^{*}\left(p^{*}\right) \equiv \mathrm{E}\left[v\left(s_{i}, s_{j}\right)\right]=\mathrm{E}[\theta]-p^{*}+\underbrace{\frac{\Delta}{2}\left(t^{*}-d^{*}\right)}_{\text {Advertising premium }}
$$

where $V^{*}\left(p^{*}\right)>0$ since $\bar{p}^{*} \leq \mathrm{E}[\theta]$ and $t^{*}>d^{*}$.

Hence, in a pooling equilibrium in which the low-quality seller invests in deceptive advertising, the buyer enjoys an 'advertising premium' that increases both with the quality differential $\Delta$ and the intensity of truthful advertising $t^{*}$, while it decreases with the intensity of deceptive advertising $d^{*}$. This is because, other things being equal, the probability of receiving a truthful ad is higher than that of being deceived - i.e., $t^{*}>d^{*}$ for any $p^{*}$ — and the value of avoiding a bad purchase equals the quality differential $\Delta$.

In the next proposition we show that the impact of the equilibrium price on the buyer's expected utility is generally ambiguous, and depends on the sensitivity of the advertising strategies to the equilibrium 
price. Recalling that $t^{*}$ and $d^{*}$ vary with $p^{*}$ according to Lemma 3 , define

$$
\tilde{\varepsilon}_{t}\left(p^{*}\right) \equiv p^{*} \frac{\partial t^{*}}{\partial p^{*}}=\frac{c^{\prime}\left(t^{*}\right)}{c^{\prime \prime}\left(t^{*}\right)}
$$

and

$$
\tilde{\varepsilon}_{d}\left(p^{*}\right) \equiv p^{*} \frac{\partial d^{*}}{\partial p^{*}}=\frac{c^{\prime}\left(d^{*}\right)+\phi}{c^{\prime \prime}\left(d^{*}\right)}
$$

These expressions denote the quasi-elasticity of advertising intensities to price - i.e., a measure of the point change in the advertising coverage due to a $1 \%$ increase of $p^{*}$.

Lemma 4. For any $p^{*} \in\left[2 \phi, \bar{p}^{*}\right]$, the buyer's expected utility features the following properties:

$$
\frac{\partial V^{*}\left(p^{*}\right)}{\partial p^{*}} \leq 0 \quad \Leftrightarrow \quad \tilde{\varepsilon}_{t}\left(p^{*}\right)-\tilde{\varepsilon}_{d}\left(p^{*}\right) \leq \frac{2 p^{*}}{\Delta} .
$$

This result shows that the impact of an increase of the pooling price $p^{*}$ on the buyer's expected utility is ambiguous. The key trade-off is the following. First, a higher price $p^{*}$ makes the buyer worseoff because, other things being equal, he pays more to get the item. Second, and most interestingly, an increase of $p^{*}$ affects the advertising premium and changes the relative likelihood of receiving a truthful ad. If the intensity of truthful advertising is always less responsive to the equilibrium price than the intensity of deceptive advertising, the buyer's expected utility decreases with $p^{*}$. However, the opposite result obtains when the intensity of truthful advertising is sufficiently more responsive to the equilibrium price than the intensity of deceptive advertising: in this case, a higher price $p^{*}$ increases the buyer's ex-ante utility because it spurs the advertising premium, and this effect is strong enough to compensate the direct (negative) effect of a larger price on the buyer's expected utility.

Lemma 4 provides a local condition that, while easy to interpret, depends on the equilibrium price in a potentially complex manner. In the next proposition we provide sufficient conditions on the shape of the penetration $\operatorname{cost} c(\cdot)$ under which $V\left(p^{*}\right)$ is either always decreasing, so that it is maximized at $2 \phi$ - i.e., the buyer always prefers the low-quality seller not to invest in deceptive advertising - or it is maximized at a price (strictly) larger than $2 \phi$ : in this case the buyer prefers some deceptive advertising.

Proposition 2. If $c^{\prime \prime \prime}(\cdot) \geq 0$, then $V^{*}\left(p^{*}\right)$ is decreasing in $p^{*}$ and it is maximized at $p^{*}=2 \phi$. If $c^{\prime \prime \prime}(\cdot)<0$, there exists a threshold $\widehat{\Delta}>0$ such that $V^{*}\left(p^{*}\right)$ is maximized at a price (strictly) larger than $2 \phi$ as long as $\Delta>\widehat{\Delta}$, where

$$
\left.\widehat{\Delta} \equiv 4 \frac{c^{\prime \prime}\left(d^{*}\right) c^{\prime \prime}\left(t^{*}\right)}{c^{\prime \prime}\left(d^{*}\right)-c^{\prime \prime}\left(t^{*}\right)}\right|_{p^{*}=2 \phi} .
$$

To gain insights about this result notice that

$$
\frac{\partial \tilde{\varepsilon}_{t}\left(p^{*}\right)}{\partial t}=\frac{1}{c^{\prime \prime}\left(t^{*}\right)^{2}}\left[c^{\prime \prime}\left(t^{*}\right)-c^{\prime}\left(t^{*}\right) c^{\prime \prime \prime}\left(t^{*}\right)\right]
$$

This condition implies that the quasi-elasticity of advertising increases with the advertising intensity 
when $c^{\prime \prime \prime}(\cdot)<0$. In this case, the buyer may actually be better-off when sellers coordinate on equilibrium prices larger than $2 \phi$ provided that $\Delta$ is large enough (so that the advertising premium is high enough). This scenario seems plausible when the sellers' penetration technology is shaped by learning-by-doing effects. Essentially, as the market price increases, the intensity of advertising of the sellers who invest more in advertising (the high-quality sellers) is more responsive than that of the sellers who advertise less (the low-quality ones). Clearly, the opposite result obtains when $c^{\prime \prime \prime}(\cdot)$ is positive or if $\Delta$ is negligible. ${ }^{26}$

It is relatively easy to find analytic examples satisfying both $c^{\prime \prime \prime}(\cdot)<0$ and $\Delta>\widehat{\Delta}$.

Example. Consider the exponential cost function $c(x)=x^{a}$ with $a \in(1,2)$. Then $c^{\prime \prime}(x)>0$ and $c^{\prime \prime \prime}(x)<0$ for all $x \in[0,1]$, while some algebra ${ }^{27}$ yields

$$
\widehat{\Delta} \equiv 4 a(a-1) \phi^{\frac{a-2}{a-1}} .
$$

Next, we consider the impact of the equilibrium price $p^{*}$ on the sellers' expected (ex-ante) profit. Recall that

$$
\pi_{h}^{*}\left(p^{*}\right)=p^{*} \frac{1+t^{*}-d^{*}}{2}-c\left(t^{*}\right)
$$

and

$$
\pi_{l}^{*}\left(p^{*}\right)=p^{*} \frac{1+d^{*}-t^{*}}{2}-c\left(d^{*}\right)-\phi d^{*}
$$

Hence, the sellers' expected profit before learning their type is

$$
\pi^{*}\left(p^{*}\right)=\frac{\pi_{h}^{*}\left(p^{*}\right)+\pi_{l}^{*}\left(p^{*}\right)}{2}=\frac{p^{*}-c\left(t^{*}\right)-c\left(d^{*}\right)-\phi d^{*}}{2} .
$$

In the next lemma we show that this expression may not be monotone with respect to $p^{*}$.

Lemma 5. For any $p^{*} \in\left[2 \phi, \bar{p}^{*}\right]$, the sellers' expected profit features the following property:

$$
\frac{\partial \pi^{*}\left(p^{*}\right)}{\partial p^{*}} \geq 0 \quad \Leftrightarrow \quad \tilde{\varepsilon}_{t}\left(p^{*}\right)+\tilde{\varepsilon}_{d}\left(p^{*}\right) \leq 2
$$

There are two effects at play. First, when $p^{*}$ increases, sellers obtain higher sales revenues in equilibrium, which raises profits. Second, when the equilibrium price increases, each seller advertises more regardless of her quality, but this tends to dissipate profits because advertising is costly. Equation (15)

\footnotetext{
${ }^{26}$ Clearly, the same argument applies to $\tilde{\varepsilon}_{d}\left(p^{*}\right)$.

${ }^{27}$ Note that $c^{\prime \prime}(x)=a(a-1) x^{a-2}$ tends to infinity as $x$ tends to zero. Thus $c^{\prime \prime}\left(d^{*}\right)$ diverges as $p^{*}$ approaches $2 \phi-$ i.e. $d^{*}$ approaches zero. Rearranging terms, we can express $\widehat{\Delta}$ as

$$
\widehat{\Delta}=\lim _{p^{*} \rightarrow 2 \phi} 4 \frac{c^{\prime \prime}\left(d^{*}\right)}{\frac{c^{\prime \prime}\left(d^{*}\right)}{c^{\prime \prime}\left(t^{*}\right)}-1}
$$

which, using de l'Hôpital and substituting $t^{*}=\left(\frac{p^{*}}{2 a}\right)^{\frac{1}{a-1}}$ and $d^{*}=\left[\frac{1}{a}\left(\frac{p^{*}}{2}-\phi\right)\right]^{\frac{1}{a-1}}$, yields the result. Thus, all the conditions necessary for the application of Proposition 2 are met.
} 
gives a local condition under which the positive sales effect prevails on the negative dissipation effect. As intuition suggests, this happens when the advertising intensities are not too sensitive to the price.

In the next proposition we provide sufficient conditions under which sellers' profits are globally increasing or decreasing with respect to the price. For any $x \in[0,1]$, let $\rho(x) \equiv c^{\prime}(x) / c^{\prime \prime}(x)$.

Proposition 3. There exist two thresholds $r$ and $R$, with $0<r<R$, such that $\pi^{*}\left(p^{*}\right)$ is increasing in $p^{*}$ if $\rho(x)<r$ for every $x \in[0,1]$ and $\pi^{*}\left(p^{*}\right)$ is decreasing in $p^{*}$ if $\rho(x)>R$ for every $x \in[0,1]$.

The interpretation of this result is straightforward. The ratio $\rho(x)$ is an inverse measure of the convexity of the penetration costs. The larger the index, the less convex the cost function $c(\cdot)$ is, and the more responsive is the seller's advertising to changes of the equilibrium price. Hence, the larger $\rho(x)$, the stronger the profit dissipation effect of advertising. As a consequence, if $\rho(x)$ is large enough, seller's profits are always decreasing in $p^{*}$ because the dissipation effect prevails. Vice versa, the revenue effect dominates when $\rho(x)$ is small enough and profits are always increasing in price.

Propositions 2 and 3 together, imply that it might be possible to find cases in which both the sellers and the buyer are better-off at prices strictly greater than the minimum price $2 \phi$.

Corollary 2. Assume that $c^{\prime \prime \prime}(\cdot)<0, \Delta>\widehat{\Delta}$ and $\rho(x)<r$ for every $x \in[0,1]$, then any (ex-ante) Pareto efficient pooling (equilibrium) price is (strictly) larger than $2 \phi$.

This result shows that, within the class of pooling equilibria with deceptive advertising, the interests of the customer and the sellers may be aligned towards prices larger than $2 \phi$.

Using the example developed above, it is not difficult to find conditions under which the requirements of Corollary 2 are met.

Example (continued). When $c(x)=x^{a}$ with $a \in(1,2)$, the condition $\rho(x)<r$ for every $x \in[0,1]$ is satisfied if a is close enough to $2 .^{28}$

\section{Equilibria with no deceptive advertising}

This section characterizes 'non-deceptive' equilibria that entail either a separating outcome, in which sellers with different qualities set different prices and do not advertise, or a different type of pooling outcome in which only the high-quality sellers advertise. We start with separating equilibria.

Separating equilibria. In a separating equilibrium prices perfectly signal qualities and sellers have no incentives to advertise. Standard undercutting arguments imply that, if a separating equilibrium exists,

\footnotetext{
${ }^{28}$ Indeed, using results from the proof of Proposition 3 , it can be checked that $\rho(x)<r$ for all $x \in[0,1]$ if

$$
\rho\left(t^{*}\right)=\frac{t^{*}}{a-1}<\min _{0 \leq d^{*}<t^{*}<1} \frac{2}{1+\left(\frac{d^{*}}{t^{*}}\right)^{2-a}}=r .
$$

This condition is certainly met for $a$ sufficiently large because, for $a$ approaching 2 from below, it becomes $t^{*}<1$.
} 
the buyer is served only by the high-quality seller who charges the price $p(h)=\Delta$, while the low-quality seller charges the most competitive price $p(l)=0$. To be supported in equilibrium, these prices must not be vulnerable to unilateral deviations. Before discussing the incentives to deviate, we specify the out-of-equilibrium beliefs. Note that deviations from this equilibrium are spotted not only when the buyer observes unexpected prices, but also when he observes unexpected ads. Since our objective is to characterize the largest possible region of parameters in which a separating outcome can emerge, we choose the off-equilibrium beliefs that make price deviations by the low-quality seller the least attractive:

A2 Whenever the buyer observes an equilibrium price by one seller (either 0 or $\Delta$ ) and a nonequilibrium price by the other (any price different from 0 or $\Delta$ ), his beliefs about sellers' qualities remain the equilibrium ones for any $\operatorname{ad}(\mathrm{s})$ he may receive from either or both sellers. If sellers charge the same price, he believes that sellers have equal probability of supplying a high-quality item, for any ad(s) he may observe.

Clearly, the low-quality seller can only deviate to the price $p(h)=\Delta$, otherwise the buyer would still recognize qualities and buy from the high-quality seller. Instead, if the low-quality seller mimics the rival by charging exactly $\Delta$, the buyer is unable to assess qualities based only upon the observation of prices. In this case, according to $\mathbf{A 2}$, he purchases from either seller with equal probability. Hence:

Proposition 4. A necessary and sufficient condition for the existence of a separating equilibrium is

$$
\mathrm{E}[\theta]<\Delta \quad \Leftrightarrow \quad \theta_{l}<\frac{\Delta}{2}
$$

To sustain a separating equilibrium in the easiest possible way it is enough to impose A2. Such a belief trivially makes deviations involving advertising unprofitable. Condition (16) is in fact directly implied by the buyer's participation constraint. That is, if the low-quality seller mimics the rival and charges $\Delta$, the buyer's out-of-equilibrium belief implies that his willingness to pay for the item is equal to the unconditional expected quality $\mathrm{E}[\theta]$, which is lower than the prevailing price $\Delta$ in the region of parameters under consideration. Hence, the buyer does not purchase out of the equilibrium path. Any other type of off-equilibrium beliefs makes price deviations by the low-quality seller more appealing, making the condition for the existence of a separating equilibrium tighter than (16).

In this equilibrium the low-quality seller makes no profits, while the profit of the high-quality seller is equal to the difference between the buyer's relative willingness to pay for the two goods: $\pi_{h}^{s}=\Delta$. Clearly, the buyer's utility is equal to that of consuming the low-quality item - i.e.,

$$
V^{s}=\theta_{h}-\Delta=\theta_{l}
$$

Finally, notice that the result stated in Proposition 4 highlights an important feature of the model: in the region of parameters in which (16) does not hold, but (8) is met, there exist only pooling equilibria 
— i.e., when

$$
\Delta>\max \left\{2 \theta_{l}, \underline{\Delta}\left(\phi, \theta_{l}\right)\right\} .
$$

This suggests that our focus on pooling equilibria in which the low-quality sellers deceive the buyer is particularly relevant in industries in which the quality differential between the items on sale is sufficiently large (i.e., $\Delta$ large), customers are particularly reluctant to buy items of low quality (i.e., $\theta_{l}$ low) and the cost of deceptive advertising is not too high ( $\phi$ small).

Pooling equilibria without deceptive advertising. Consider now pooling equilibria in which the low-quality seller does not advertise while the high-quality seller advertises but does not fully cover the market. ${ }^{29}$ Following a logic similar to that developed in Proposition 1 and imposing the same off-equilibrium beliefs, we can state the following result:

Proposition 5. There always exists a class of (symmetric) pooling equilibria in which trade occurs with certainty and only the high-quality seller advertises. These equilibria have the following features. The intensity of truthful advertising ( $\left.t^{* *}\right)$ chosen by the high-quality seller in equilibrium satisfies $c^{\prime}\left(t^{* *}\right)=$ $p^{* *} / 2$, with $t^{* *}<1$, for any equilibrium price $p^{* *}$. Both sellers charge a price $p^{* *} \in\left[0, \bar{p}^{* *}\right]$, with

$$
\bar{p}^{* *}=\min \{2 \phi, p(\Delta), \mathrm{E}[\theta]\},
$$

where $p(\Delta)$ solves the incentive compatibility constraint of the low-quality seller as an equality - i.e.,

$$
p^{* *} \frac{1-t^{* *}}{2}=p^{* *}-\Delta
$$

The buyer's equilibrium strategy is the same as that stated in Lemma 2.

This result shows that whenever the game features pooling equilibria in which the buyer is deceived, it also features pooling equilibria in which the buyer is not deceived. This multiplicity opens a selection issue that we address in the next section, where we argue that there are plausible cases in which sellers are likely to coordinate on the 'deceptive' equilibria.

Notice that $p^{*}=2 \phi$ is a pooling equilibrium belonging to the equilibrium class just characterized: at such a price low-quality sellers do not advertise and the buyer is never deceived. As noted earlier, we have included this particular price in both classes of pooling equilibria for easiness of exposition.

Finally, notice that in these equilibria the sellers' expected profit is

$$
\pi^{* *}\left(p^{* *}\right)=\frac{1}{2}\left[p^{* *}-c\left(t^{* *}\right)\right]
$$

\footnotetext{
${ }^{29}$ Notice that, because of the Inada conditions, the high-quality seller has no incentive to fully cover the market - i.e., for $c^{\prime}(1)$ sufficiently large, $t<1$ for every $p \leq \mathrm{E}[\theta]$.
} 
while the buyer's expected utility is

$$
V^{* *}\left(p^{* *}\right)=\mathrm{E}[\theta]-p^{* *}+\frac{\Delta}{2} t^{* *}
$$

Using the same techniques as in the proof of Lemma 5, it can be verified that the sellers' expected profit $\pi^{* *}$ is increasing (resp. decreasing) in $p^{* *}$ if $\tilde{\varepsilon}_{t}\left(p^{* *}\right)<2$ (resp. $>$ ) for every $p^{* *} \in[0,2 \phi]$. The buyer expected utility is increasing in $p^{* *}$ if $\Delta$ is large enough, and decreasing otherwise. In fact, if $\Delta$ is large enough, the impact of a higher price on the advertising premium dominates the negative direct price effect, and vice versa. Noteworthy, while in deceptive equilibria the advertising premium can be either decreasing or increasing with respect to the equilibrium price (as stated in Proposition 2), in this case it is unambiguously increasing.

\section{Equilibrium selection and buyer's welfare}

Given the multiplicity of equilibria highlighted in the previous section, we now provide conditions under which sellers prefer to coordinate on deceptive equilibria. Moreover, we study the implications of this selection analysis on the buyer's expected utility.

\subsection{Selection}

Recall that within every class of pooling outcomes discussed above there is a continuum of prices that can be supported in equilibrium. To address the multiplicity issue, we first define a selection criterion. One reasonable hypothesis is that sellers select the equilibrium they will coordinate upon before knowing their types. Accordingly, an intuitive selection criterion is that sellers coordinate on the equilibrium that

yields the highest expected (ex-ante) profit. ${ }^{30}$ Using this criterion, we will show that there are plausible cases in which the selected equilibrium is the one in which the low-quality seller deceives the buyer.

Pooling with vs. pooling without deceptive advertising. In the previous section we have shown that there exists a non-empty region of parameters in which separating equilibria do not exist (see condition (17)). Instead, pooling equilibria with and without deceptive advertising always coexist. A natural question is then which pooling equilibrium is selected between those with and without deception.

Comparing the expression of $\pi^{*}\left(p^{*}\right)$ in (14) with that of $\pi^{* *}\left(p^{* *}\right)$ in (18) is hard in general. The reason is twofold. On the one hand, the class of pooling equilibria with positive deception features higher prices relative to those with truthful advertising only. On the other hand, in these equilibria there is a higher investment in advertising which tends to dissipate profits. It is generally impossible to determine which of these contrasting effects dominates, unless more structure is imposed on the penetration cost $c(\cdot)$.

\footnotetext{
${ }^{30}$ This hypothesis can be rationalized with a standard repeated-game type of argument.
} 
Clearly, if the sellers' expected profit increases in price for both types of pooling equilibria — i.e., if

$$
\tilde{\varepsilon}_{t}(p)+\tilde{\varepsilon}_{d}(p) \leq 2 \quad \forall p \in\left[0, \bar{p}^{*}\right],
$$

then sellers want to engage in deceptive advertising and select the highest equilibrium price. ${ }^{31}$ That is

$$
\max _{p^{*} \in\left[2 \phi, \bar{p}^{*}\right]} \pi^{*}\left(p^{*}\right)>\max _{p^{* *} \in[0,2 \phi]} \pi^{* *}\left(p^{* *}\right) .
$$

This is because $\pi^{*}\left(p^{*}\right)=\pi^{* *}\left(p^{* *}\right)$ at $p^{*}=p^{* *}=2 \phi{ }^{32}$ According to Proposition 3 this happens when the penetration cost is (globally) not too convex. This requirement is, however, too demanding in applications as it forces $\rho(x)$ to be small enough for all $x \in[0,1]$. In the next proposition we provide milder conditions under which (21) is always met.

Proposition 6. If $c^{\prime \prime \prime}(\cdot)$ has a constant sign and (20) holds at $p=2 \phi$, then (21) is always met.

Noteworthy, Proposition 6 applies to the standard quadratic case - e.g., when $c(x)=k x^{2} / 2$ (see the Appendix). Hence, in this case (which is often considered in applications) sellers unambiguously prefer to coordinate on deceptive equilibria.

Pooling vs. separating equilibria. We now consider the region of parameters in which the game features also separating equilibria. For simplicity, let us focus on the most interesting case in which sellers prefer the pooling equilibrium with deception, and consider the 'regular' case in which $\pi^{*}\left(p^{*}\right)$ is increasing in $p^{*}$.

The sellers' expected profits in a separating equilibrium are

$$
\pi^{s}=\frac{\Delta}{2}
$$

Therefore, sellers prefer the pooling to the separating outcome if the following sufficient condition holds

$$
\pi^{*}(2 \phi) \geq \pi^{s}
$$

This leads us to the following result.

Proposition 7. Sellers prefer to coordinate on the pooling equilibrium with positive deception rather than on the separating equilibrium if

$$
\Delta\left(\phi, \theta_{l}\right)<\Delta \leq 2 \phi-c\left(c^{\prime-1}(\phi)\right) .
$$

\footnotetext{
${ }^{31}$ Recall that $\tilde{\varepsilon}_{d}(p)=0$ for every $p<2 \phi$.

${ }^{32}$ Notice that equilibrium profits are continuous yet not differentiable at $p^{*}=2 \phi$, as right and left derivatives at $p^{*}=2 \phi$ are defined but different.
} 
The economic intuition behind this result is as follows: pooling equilibria in which the buyer is deceived exist only if the quality differential $\Delta$ is large enough as previously explained. Hence, the lower bound. However, when this differential becomes too large, the profit that a seller enjoys in a separating equilibrium when she is of high-quality type becomes so large that, for higher $\Delta$ 's, sellers prefer to coordinate on the separating outcome.

\subsection{The buyer's welfare}

We now study what type of equilibrium maximizes the buyer's expected utility (provided that sellers selected the outcome that yields the highest expected profit). Again, we first compare the buyer's expected utility in the pooling equilibria with and without deception, and then discuss the separating equilibrium.

The comparison between the buyer's expected utility in (11) and in (19) is not easy in general. The reason is that $p^{*}>p^{* *}$ and $t^{* *}<t^{*}$ : the pooling price is certainly lower when only the high-quality seller advertises in equilibrium, but this also implies that the advertising premium that the buyer enjoys might be larger when the selected equilibrium features deceptive advertising.

To get clear-cut predictions, we focus again on the quadratic example. In this case, regardless of the type of pooling equilibrium, the sellers' expected profit is increasing in the price. Moreover, Proposition 2 implies that in the quadratic case - i.e., for $c^{\prime \prime \prime}(\cdot)=0$ - the buyer's expected utility $V^{*}\left(p^{*}\right)$ is always decreasing in $p^{*}$, so that:

$$
V^{*}\left(\bar{p}^{*}\right)<V^{*}(2 \phi)=V^{* *}(2 \phi) .
$$

This inequality suggests that the buyer's and the sellers' objectives are not aligned: the buyer prefers not to be deceived, while sellers prefer to coordinate on the equilibrium with deceptive advertising. As a consequence, a regulatory agency concerned with buyer protection, may want to ban deceptive advertising and implement policies that raise the additional (marginal) cost $\phi$ of airing a misleading ad. This would force sellers to switch from the equilibrium with deceptive advertising to the one with truthful advertising only. Formally, this can be done by setting $\phi$ high enough to break condition (8) i.e.,

$$
\phi>\frac{k}{2}\left[\sqrt{1+\frac{4 \Delta}{k}}-1\right] .
$$

In this case, within the class of symmetric equilibria without market breakdown, the unique solution of the game is a pooling outcome with no deceptive advertising.

However, this policy implication is valid only in the region of parameters in which the game does not feature separating equilibria. Indeed, if the separating equilibrium exists, destroying pooling equilibria with deceptive advertising may not benefit the buyer. This is so, in particular, if sellers coordinate on the separating equilibrium (rather than on the pooling equilibrium without deception), and if the buyer's expected utility is lower at the separating than at the deceptive pooling equilibrium. Formally, 
this scenario emerges if

$$
\pi^{s}>\max _{p^{* *} \in(0,2 \phi]} \pi^{* *}\left(p^{* *}\right)
$$

and

$$
V^{s}<V^{*}\left(\bar{p}^{*}\right)
$$

In the next proposition we show that there exists a non-empty region of parameters in which both conditions are satisfied.

Proposition 8. Suppose that $c(x)=k x^{2} / 2$. A sufficient condition for both (23) and (24) to hold is

$$
\Delta>\max \left\{\frac{\phi}{2 k}(4 k-\phi), 4 \frac{k^{2}}{k+\phi}\right\} .
$$

In the separating equilibrium, the seller who offers the better product gets a premium that is increasing with the quality differential $\Delta$ - i.e., the high-quality seller exploits a sort of "monopolistic power" to extract more surplus from the buyer. When this premium is large enough, the buyer may actually prefer to be deceived with some probability rather than knowing the quality purchased in the separating equilibrium. Hence, when the game features three types of equilibria, a policy that completely prevents low-quality firms from airing false claims may actually do worse than a laissez faire approach.

\section{Endogenous sanctions}

In the previous section we argued that it is relatively easy to construct examples in which a regulatory agency concerned with buyer protection may not support a complete shut down of the pooling equilibria with deceptive advertising. Here we highlight a different policy implication of our model. We show that, if the (expected) sanction $\phi$ can be endogenously chosen by such an agency, the policy that maximizes the buyer's expected utility is more lenient than the policy that maximizes total (expected) welfare.

Suppose that a regulatory agency can enforce a sanction $\phi$ by paying the (increasing and convex) enforcement cost $e(\phi) .{ }^{33}$ We make the following simplifying assumptions. First, we consider the 'regular' case in which the sellers' expected profits increase with the equilibrium price ${ }^{34}$ while the buyer's expected utility decreases with it. Hence, sellers prefer deceptive to non-deceptive equilibria. Moreover, we posit that $e^{\prime}(\cdot)$ is large enough that the Authority never finds it convenient to set $\phi$ so high to completely shut down equilibria with deceptive advertising. ${ }^{35}$ Finally, we assume that $e^{\prime \prime}(\cdot)$ is large enough that the buyer's expected utility and total (expected) welfare, net of the enforcement cost, are single peaked

\footnotetext{
${ }^{33}$ Such cost reflects the Authority's prosecution effort or, in other words, the cost of building a given deterrence power.

${ }^{34}$ This means that sellers always prefer the pooling equilibrium with deceptive advertising to that with truthful advertising only, and that they charge the maximal pooling price. The result still holds if they coordinate on any price strictly lower than that.

${ }^{35}$ Formally, this requires $e^{\prime}(\cdot)$ to be large enough at $\phi$ such that condition (8) holds as equality. However, an alternative assumption is that $\phi$ cannot exceed the actual damage caused to the buyer, that is, the quality differential $\Delta$. In fact, it is easy to verify that condition (8) still holds at $\phi=\Delta$.
} 
with respect to $\phi .^{36}$

The Authority announces (and commits to) an expected sanction $\phi$ at the outset of the game. The timing is otherwise unchanged. Consider first a policy that maximizes the buyer's expected utility net of the enforcement cost - i.e.,

$$
V^{*}\left(\bar{p}^{*}\right)-e(\phi) \equiv \mathrm{E}[\theta]-\bar{p}^{*}+\frac{\Delta}{2}\left[t^{*}\left(\bar{p}^{*}\right)-d^{*}\left(\bar{p}^{*}, \phi\right)\right]-e(\phi),
$$

where, for the sake of clarity, we have made explicit the link between the advertising intensities, the equilibrium pooling price and the expected fine $\phi$ through the functions $t^{*}\left(\bar{p}^{*}\right)$ and $d^{*}\left(\bar{p}^{*}, \phi\right)$.

Differentiating with respect to $\phi$, it is easy to verify that the expected sanction that maximizes (25) $\left(\right.$ say $\left.\phi^{b}\right)$ solves the following first-order condition

$$
\underbrace{\frac{\partial \bar{p}^{*}}{\partial \phi}\left[-1+\frac{\Delta}{4} \frac{\partial}{\partial \bar{p}^{*}}\left[t^{*}\left(\bar{p}^{*}\right)-d^{*}\left(\bar{p}^{*}, \phi\right)\right]\right]}_{\geq 0}-\underbrace{\frac{\Delta}{4} \frac{\partial d^{*}\left(\bar{p}^{*}, \phi\right)}{\partial \phi}}_{<0}=e^{\prime}(\phi),
$$

Equation (26) shows that the impact of $\phi$ on the buyer's expected utility has two main effects (going in the same direction). First, increasing the cost of deceptive advertising tends to reduce the maximal pooling prices, which, other things being equal, makes the buyer better-off since we have assumed that his expected utility is decreasing in the equilibrium price. Second, when $\phi$ increases, the intensity of deceptive advertising chosen by the low-quality seller diminishes, which tends to increase the advertising premium and to make the buyer better-off. Clearly, the sum of these two effects needs to be traded off with the enforcement cost.

Next, consider an Authority that is concerned with total (expected) welfare - i.e., the sum of the buyer's expected utility and the sellers' expected profits plus the (expected) revenue $\phi d^{*}$ collected from the low-quality sellers (which we assume to be redistributed to the society and not necessarily to the buyer through, e.g., the provision of public goods). Formally:

$$
W\left(\bar{p}^{*}, \phi\right)=\mathrm{E}[\theta]+\frac{\Delta}{2}\left[t^{*}\left(\bar{p}^{*}\right)-d^{*}\left(\bar{p}^{*}, \phi\right)\right]-c\left(t^{*}\left(\bar{p}^{*}\right)\right)-c\left(d^{*}\left(\bar{p}^{*}, \phi\right)\right)-e(\phi) .
$$

Clearly, the equilibrium price has no direct impact on total welfare: it is just a monetary transfer between the buyer and the sellers. Differentiating with respect to $\phi$, it is easy to verify that the sanction which maximizes total welfare (say $\phi^{w}$ ) solves the following first-order condition

$$
\begin{aligned}
& e^{\prime}(\phi)=\frac{\partial \bar{p}^{*}}{\partial \phi}\left[\frac{\Delta}{4} \frac{\partial}{\partial \bar{p}^{*}}\left(t^{*}\left(\bar{p}^{*}\right)-d^{*}\left(\bar{p}^{*}, \phi\right)\right)\right]-\frac{\Delta}{4} \frac{\partial d^{*}\left(\bar{p}^{*}, \phi\right)}{\partial \phi}- \\
& \frac{\partial \bar{p}^{*}}{\partial \phi}\left[c^{\prime}\left(t^{*}\left(\bar{p}^{*}\right)\right) \frac{\partial t^{*}\left(\bar{p}^{*}\right)}{\partial \bar{p}^{*}}+c^{\prime}\left(d^{*}\left(\bar{p}^{*}, \phi\right)\right) \frac{\partial d^{*}\left(\bar{p}^{*}, \phi\right)}{\partial \bar{p}^{*}}\right]-c^{\prime}\left(d^{*}\left(\bar{p}^{*}, \phi\right)\right) \frac{\partial d^{*}\left(\bar{p}^{*}, \phi\right)}{\partial \phi} .
\end{aligned}
$$

\footnotetext{
${ }^{36}$ It can be verified that all these conditions can be jointly satisfied in the quadratic example developed above.
} 
A higher $\phi$ not only impacts the advertising premium (as discussed above), but it also affects the total costs of advertising. These costs decrease because the maximal pooling price $\bar{p}^{*}$ is (weakly) decreasing in $\phi$, and the advertising intensities decrease if the equilibrium price becomes lower.

Proposition 9. Buyer protection requires less enforcement than welfare maximization - i.e., $\phi^{b}<\phi^{w}$.

This result offers the surprising prediction that the more an Authority cares about buyers, the less it should protect them from deceptive advertising. The reason is that the buyer does not internalize the cost saving effect of an increased sanction $\phi$, which may induce sellers to invest less in advertising.

\section{Extensions}

This section provides two extensions of the baseline model. First, we show that the main qualitative features of the equilibrium with deceptive advertising characterized in the baseline model extend to a framework in which the sellers' types are imperfectly correlated. Second, we show that the game may also feature pooling equilibria with market breakdown - i.e., outcomes in which the buyer purchases one of the items on sale only in some states. We find sufficient conditions under which the main conclusions of the baseline model are with no loss of insights.

\subsection{Weakly correlated types with private information}

In this section we show that the characterization of the equilibria with deceptive advertising provided in Proposition 1 survives when the two types of sellers are not perfectly correlated.

We relax the assumption that types are perfectly negatively correlated by assuming that one seller provides a high-quality good, observable by the rival, and the rival has private information on its own good quality. The probability that the latter provides a low-quality good is $\varrho$. As before, the buyer cannot distinguish the quality of sellers. Notice that in this extended version of the game there are three types of sellers: the surely high-quality seller, denoted by $H$, the probabilistically high-quality seller, denoted by $h$, and the low-quality seller, denoted by $l$. Hence, with probability $(1-\varrho)$ both sellers provide high-quality goods and do not deceive the buyer. We denote their advertising strategies as $t_{H}$ and $t_{h}$ respectively. Finally, with probability $\varrho$ there is a low-quality seller whose deceptive advertising strategy is denoted by $d$.

Even though this model is more general than the perfectly correlated type one, the results are substantially the same. We summarize them in the following proposition.

Proposition 10. When the sellers' types are not perfectly (negatively) correlated there exists a set of (symmetric) weak PBE in which trade occurs with certainty, sellers charge the same price $\left(p^{*}\right)$, and the low-quality firm deceives the customer $\left(d^{*}>0\right)$ if and only if $\Delta>\Delta\left(\phi, \theta_{l}\right)$. The equilibrium characterization is identical to that of Proposition 1. Both sellers charge a price $p^{*} \in\left[2 \phi, \bar{p}^{*}\right]$. The 
maximal pooling price that can be charged in these equilibria is:

$$
\bar{p}^{*}=\min \{p(\phi, \Delta), \mathrm{E}[\theta]\}
$$

where $p(\phi, \Delta)$ is defined exactly as in Proposition 1.

For any $p^{*} \in\left[2 \phi, \bar{p}^{*}\right]$, the equilibrium advertising strategies are such that $t_{H}^{*}=t_{h}^{*}=t^{*}>d^{*} \geq 0$ and $t^{*}$ and $d^{*}$ satisfy the first-order conditions stated in Lemma 3. The buyer's equilibrium strategy is the same as that stated in Lemma 2.

Hence, the characterization of deceptive equilibria is robust to the introduction of imperfect correlation between sellers' types. The only notable difference is that the equilibrium profit of the surely high-quality seller, type $H$, is now increasing in the probability, $\varrho$, that the opponent sells a low-quality item - i.e. has type $l .^{37}$ This is because a low-quality seller advertises less strongly in equilibrium than a high-quality seller, thereby increasing the chances that the surely high-quality seller, $H$, makes the sale. Indeed, as $\varrho$ tends to 1 , the model reverts to the perfectly correlated one and equilibrium profits converge to those characterized in (12) and (13).

\subsection{Equilibria with market breakdown}

In this section we briefly discuss the class of equilibria in which the buyer refrains from purchasing in some states: the market breaks down. For brevity, we consider again the quadratic example and assume that sellers' qualities are perfectly (negatively) correlated. Out-of-equilibrium beliefs are as in A1. We want to show that there exists a non-empty region of parameters in which equilibria with market breakdown do not exist, but the game features equilibria of the type described in Section 5 .

Consider a candidate equilibrium in which the low-quality seller's deceptive advertising is $\tilde{d}>0$ while the high-quality seller invests $\tilde{t}$ in truthful advertising. Let $\tilde{p}$ be the equilibrium price. Suppose that in this equilibrium the market breaks down in some states of nature - i.e., there exists at least a pair of signals $\left(s_{i}, s_{j}\right)$ such that

$$
\tilde{p}>\mathrm{E}\left[\theta \mid s_{i}, s_{j}\right]
$$

otherwise trade would occur with probability 1. Given the buyer's posteriors defined in equations (1)-(4), this outcome can occur only if

$$
\tilde{p}>\mathrm{E}[\theta \mid \varnothing, \varnothing]=\mathrm{E}[\theta \mid h, h]=\theta_{l}+\frac{\Delta}{2},
$$

and $\tilde{p} \leq \mathrm{E}[\theta \mid h, \varnothing]<\theta_{h}$, otherwise there would be full market breakdown (which clearly cannot be an equilibrium outcome).

Following the logic developed throughout the paper, it is easy to show that in every (symmetric) pooling equilibrium with market breakdown the buyer's strategy satisfies the following properties: $(i)$

\footnotetext{
${ }^{37}$ See the Appendix for details of this comparative statics.
} 
symmetry - i.e., $\tilde{\alpha}_{i}\left(s, s^{\prime}\right)=\tilde{\alpha}_{j}\left(s, s^{\prime}\right)$ for every $\left(s, s^{\prime}\right)$; $(i i)$ when the buyer receives only one ad he buys from the seller who has aired that ad - i.e., $\tilde{\alpha}_{i}(h, \varnothing)=1$ (resp. 0) if and only if $\tilde{t}>\tilde{d}$ (resp. $<$ ); and (iii) when the buyer receives two identical signals he does not purchase the item - i.e., $\tilde{\alpha}_{i}(s, s)=0$.

The economic intuition of this result is as in Lemma 2: since sellers are ex-ante identical, a symmetric equilibrium exists if and only if the buyer treats them symmetrically at the interim stage. The only remarkable difference is point $(i i i)$ : the buyer does not purchase the item when he receives two identical signals. Hence, for any price $\tilde{p}$ charged in equilibrium, the sellers' profits are

$$
\begin{aligned}
\tilde{\pi}_{h}(\tilde{p}) & =\tilde{p}(1-\tilde{d}) \tilde{t}-\frac{k}{2} \tilde{t}^{2}, \\
\tilde{\pi}_{l}(\tilde{p}) & =\tilde{p}(1-\tilde{t}) \tilde{d}-\frac{k}{2} \tilde{d}^{2}-\phi \tilde{d} .
\end{aligned}
$$

The first-order conditions with respect to $\tilde{t}$ and $\tilde{d}$ are, respectively

$$
\begin{aligned}
\tilde{p}(1-\tilde{d}) & =k \tilde{t} \\
\tilde{p}(1-\tilde{t}) & =k \tilde{d}+\phi
\end{aligned}
$$

These conditions highlight an important difference with the analysis developed so far: truthful and deceptive advertising are strategic substitutes - i.e., when $\tilde{d}$ increases, $\tilde{t}$ must decrease and vice versa.

To rule out equilibria with corner solutions we impose the intuitive sufficient condition $\theta_{h}<k$, so that $\tilde{p}<\theta_{h}<k$. This implies that at an interior solution

$$
\begin{aligned}
\tilde{t} & =\frac{\tilde{p}}{k+\tilde{p}}+\frac{\tilde{p} \phi}{(k-\tilde{p})(k+\tilde{p})}, \\
\tilde{d} & =\frac{\tilde{p}}{k+\tilde{p}}-\frac{\phi k}{(k-\tilde{p})(k+\tilde{p})},
\end{aligned}
$$

where it can be readily verified that $1>\tilde{t}>\tilde{d}$. An interesting difference with the previous analysis is that $\tilde{d}>0$ if and only if $\tilde{p} \in\left(\tilde{p}_{0}, \tilde{p}_{1}\right)$, with

$$
\tilde{p}_{0}=\frac{k-\sqrt{k(k-4 \phi)}}{2}<\frac{k+\sqrt{k(k-4 \phi)}}{2}=\tilde{p}_{1},
$$

which are defined only if $\phi<k / 4$. Hence, the low-quality seller has an incentive to invest in deceptive advertising if and only if the equilibrium price is neither too low nor too high. The reason is simple. If the equilibrium price is too small, the low-quality seller has no incentive to invest in deceptive advertising (as seen before). However, when the market breaks down, the sellers' advertising choices are strategic substitutes. Hence, if the equilibrium price is too high, the high-quality seller's investment in truthful advertising crowds out the low-quality seller's incentive to advertise. Therefore, in order to have deceptive 
advertising in equilibrium, the pooling price must be not too large. Equilibrium profits are

$$
\begin{aligned}
\tilde{\pi}_{h}(\tilde{p}) & =\frac{k \tilde{p}^{2}}{2(k+\tilde{p})^{2}(\tilde{p}-k)^{2}}(k-\tilde{p}+\phi)^{2}, \\
\tilde{\pi}_{l}(\tilde{p}) & =\frac{k \tilde{p}^{2}}{2(k+\tilde{p})^{2}(\tilde{p}-k)^{2}}\left[k-\tilde{p}-\frac{k}{\tilde{p}} \phi\right]^{2},
\end{aligned}
$$

where it is easy to verify that $\tilde{\pi}_{h}(\tilde{p})>\tilde{\pi}_{l}(\tilde{p})$ in the region of parameters under consideration. Hence, the equilibrium characterization follows the same steps as in Section 5. That is, the relevant incentive constraint to consider is that of the low-quality seller — i.e.,

$$
\tilde{\pi}_{l}(\tilde{p})=\frac{k \tilde{p}^{2}}{2(k+\tilde{p})^{2}(\tilde{p}-k)^{2}}\left[k-\tilde{p}-\frac{k}{p} \phi\right]^{2} \geq \pi^{d}(\tilde{p})=\tilde{p}-\Delta .
$$

As long as this inequality defines a non-empty set, the outcome described so far is a weak PBE.

Notice that $\tilde{\pi}_{l}(\tilde{p})=0$ for $\tilde{p}=\tilde{p}_{0}$. Moreover, in the region of parameters under consideration, it can be verified that $\tilde{\pi}_{l}(\tilde{p})$ is an increasing function of $\tilde{p}$ and $\partial \tilde{\pi}_{l}(\tilde{p}) / \partial \tilde{p}<1$. Hence, a sufficient condition under which equation (27) defines an empty set is,

$$
\Delta<\tilde{\Delta}(\phi) \equiv \frac{k-\sqrt{k(k-4 \phi)}}{2}
$$

meaning that $\pi^{d}(\tilde{p})>0$ at $\tilde{p}=\tilde{p}_{0}$. This suggests that, as long as $\underline{\Delta}\left(\phi, \theta_{l}\right)<\tilde{\Delta}(\phi)$, there exists a non empty region of parameters such that the game features a pooling equilibrium in which trades occurs with certainty, but not an equilibrium with market breakdown. For example, if

$$
\underline{\Delta}\left(\phi, \theta_{l}\right)=2\left(2 \phi-\theta_{l}\right)
$$

it is easy to verify that $\tilde{\Delta}(\phi)-\underline{\Delta}\left(\phi, \theta_{l}\right)=2 \theta_{l}>0$. Hence, in this region of parameters the analysis developed so far apply without loss of insights.

\section{Concluding remarks}

We studied a simple game in which two sellers supplying experience goods of different quality can induce a perspective buyer into a bad purchase through (costly) deceptive advertising. The core contribution of the paper is the characterization of a class of pooling equilibria in which low-quality sellers deceive a buyer that is Bayes-rational and makes his purchase decision on the basis of the available information. Although in these outcomes low-quality goods are purchased with positive probability, the buyer's expected utility can be higher than in a fully separating equilibrium in which he purchase the high-quality good for sure. This relies on a novel pro-competitive effect due to the buyers' ignorance about sellers' product qualities. It is also shown that, under general conditions, within the class of equilibria in which the buyer is deceived, 
Pareto efficiency may require relatively high prices - i.e., the buyer may prefer higher prices than the minimum price within that class. Moreover, although the game may feature other types of equilibria that entail no deceptive advertising (requiring either pooling or separating behavior at the pricing stage) we provide sufficient conditions under which sellers are more likely to coordinate on equilibria with wasteful deceptive advertising. Finally, as a normative exercise, we have analyzed a simple policy that involves the enforcement of deterrence effort against misleading and deceptive conducts. We found that total welfare maximization requires stronger deterrence relative to consumer welfare maximization. 


\section{References}

Akerlof, G. A. (1970): "The Market for "Lemons": Quality Uncertainty and the Market Mechanism," Quarterly Journal of Economics, 84(3), 488-500.

Anderson, S. P., and R. Renault (2006): "Advertising Content," American Economic Review, 96(1), 93-113.

(2009): "Comparative advertising: disclosing horizontal match information," The RAND Journal of Economics, 40(3), 558-581.

Bagwell, K. (2007): "The Economic Analysis of Advertising," in Handbook of Industrial Organization, ed. by M. Armstrong, and R. Porter, vol. 3 of Handbook of Industrial Organization, chap. 28, pp. 1701 - 1844. Elsevier.

Bagwell, K., and G. Ramey (1988): "Advertising and Limit Pricing," The RAND Journal of Economics, 19(1), 59-71.

(1991): "Oligopoly Limit Pricing," The RAND Journal of Economics, 22(2), 155-172.

Bagwell, K., and M. H. Riordan (1991): "High and Declining Prices Signal Product Quality," American Economic Review, 81(1), 224-239.

Banerjee, B., and S. Bandyopadhyay (2003): "Advertising Competition Under Consumer Inertia," Management Science, 22(1), 131 Ü144.

Banks, J. S., And J. Sobel (1987): "Equilibrium Selection in Signaling Games," Econometrica, 55(3), 647-661.

Barigozzi, F., P. G. Garella, and M. Peitz (2009): "With a Little Help from My Enemy: Comparative Advertising as a Signal of Quality," Journal of Economics $\mathscr{G}$ Management Strategy, 18(4), $1071-1094$.

Becker, G. S. (1968): "Crime and Punishment: An Economic Approach," Journal of Political Economy, 76(2), Crime and Punishment: An Economic Approach.

Becker, G. S., And K. M. Murphy (1993): "A Simple Theory of Advertising as a Good or Bad," Quarterly Journal of Economics, 108(4), 941-964.

Cabral, L. M. B. (2000): "Stretching firm and brand reputation," The RAND Journal of Economics, 31(4), 658 Ü673.

Chamberlin, E. H. (1933): The Theory of Monopolistic Competition: A Re-orientation of the Theory of Value, vol. 38 of Harvard Economic Studies. Harvard University Press.

Cho, I.-K., And D. M. Kreps (1987): "Signaling Games and Stable Equilibria," Quarterly Journal of Economics, 102(2), 179-221.

Chu, W. (1992): "Demand Signalling and Screening in Channels of Distribution," Marketing Science, $11(4), 327-347$.

Corts, K. S. (2012): "Prohibitions on False and Unsubstantiated Claims: Inducing the Acquisition and Revelation of Information through Competition Policy," mimeo. 
(2013): "Prohibitions on False and Unsubstantiated Claims: Inducing the Acquisition and Revelation of Information through Competition Policy," Journal of Law and Economics, 52(2), 453486.

(2014): "The social value of information on product quality," Economics Letters, 122, 140-143. forthcoming.

(2015): "Finite Optimal Penalties for False Advertising," Journal of Industrial Economics,

Daughety, A. F., And J. F. Reinganum (2008): "Communicating quality: a unified model of disclosure and signalling," The RAND Journal of Economics, 39(4), 973-989.

Dixit, A., And V. Norman (1978): "Advertising and Welfare," The Bell Journal of Economics, 9(1), $1-17$.

Ellison, G. (2005): “A Model of Add-On Pricing," Quarterly Journal of Economics, 120(2), 585-637.

FArrell, J. (1986): "Voluntary Disclosure: Robustness of the Unraveling Result, and Comments on Its Importance," in Antitrust and Regulation, ed. by R. E. Grieson, pp. 91-103. Lexington Books.

Fudenberg, D., and J. Tirole (1991): Game Theory. Mit Press, Cambridge, MA.

Galeotti, A., and J. L. Moraga-GonzÁlez (2008): "Segmentation, advertising and prices," International Journal of Industrial Organization, 26(5), 1106-1119.

Grossman, G. M., and C. Shapiro (1984): "Informative Advertising with Differentiated Products," Review of Economic Studies, 51(1), 63-81.

Hastak, M., and M. B. Mazis (2011): "Deception by Implication: A Typology of Truthful but Misleading Advertising and Labeling Claims," Journal of Public Policy \&5 Marketing, 30(2), 157-167.

Hattori, K., and K. Higashida (2012): “Misleading Advertising in Duopoly," Canadian Journal of Economics, 45(3), 1154-1187.

Heidhues, P., B. Kőszegi, and T. Murooka (2012): “The Market for deceptive Products,” mimeo.

Johnson, J. P., And D. P. Myatt (2006): "On the Simple Economics of Advertising, Marketing, and Product Design," American Economic Review, 96(3), 756-784.

Kotowitz, Y., and F. Mathewson (1979): "Advertising, Consumer Information, and Product Quality," The Bell Journal of Economics, 10(2), 566-588.

Leland, H. E. (1979): "Quacks, Lemons, and Licensing: A Theory of Minimum Quality Standards," Journal of Political Economy, 87(6), 1328-1346.

Lewis, T. R., and D. E. M. Sappington (1994): "Supplying Information to Facilitate Price Discrimination," International Economic Review, 35(2), 309-327.

Martimort, D., and H. Moreira (2010): "Common agency and public good provision under asymmetric information," Theoretical Economics, 5(2), 159-213.

Mas-Colell, A., M. D. Whinston, and J. R. Green (1995): Microeconomic Theory. Oxford University Press. 
Matthews, S., and A. Postlewaite (1985): "Quality Testing and Disclosure," The RAND Journal of Economics, 16(3), 328-340.

Miklós-Thal, J., And J. Zhang (2013): “(De)marketing to Manage Consumer Quality Inferences," Journal of Marketing Research, forthcoming.

Milgrom, P., And J. Roberts (1986): "Price and Advertising Signals of Product Quality," Journal of Political Economy, 94(4), 796-821.

Nelson, P. (1974): “Advertising as Information," Journal of Political Economy, 82(4), 729-754.

Orzach, R., P. B. Overgaard, and Y. Tauman (2002): "Modest Advertising Signals Strength," The RAND Journal of Economics, 33(2), 340-358.

Piccolo, S., P. Tedeschi, and G. Ursino (2014a): "Deceptive Advertising with Rational Buyers," mimeo.

(2014b): "How Limiting Deceptive Practices Harms Consumers," mimeo.

Pieters, R., L. Warlop, and M. Wedel (2002): "Breaking Through the Clutter: Benefits of Advertisement Originality and Familiarity for Brand Attention and Memory," Management Science, 48(6), $765-781$.

Polinsky, M., And S. Shavell (2012): "Mandatory Versus Voluntary Disclosure of Product Risks," The Journal of Law, Economics, \& Organization, 28(2), 360-379.

Salop, S. C., And D. T. Scheffman (1983): "Raising Rivals' Costs," American Economic Review, 73(2), 267-271, Papers and Proceedings of the Ninety-Fifth Annual Meeting of the American Economic Association.

Sauer, R. D., And K. B. Leffler (1990): "Did the Federal Trade Commission's Advertising Substantiation Program Promote More Credible Advertising?," American Economic Review, 80(1), 191-203.

Shavell, S. (1984): "A model of the optimal use of liability and safety regulation," The RAND Journal of Economics, 15(2), 271-280.

(1994): "Acquisition and disclosure of information prior to sale," The RAND Journal of Economics, 25(1), 20-36.

Wang, C. (2011): "Informative Advertising, Consumer Search and Transparency Policy," mimeo.

Wernerfelt, B. (1988): "Umbrella Branding as a Signal of New Product Quality: An Example of Signalling by Posting a Bond," The RAND Journal of Economics, 19(3), 458-466.

(1994): "Selling Formats for Search Goods," Marketing Science, 13(3), 298-309.

WiLSON, L. (2000): The advertising law guide: a friendly desktop reference for advertising professionals. Allworth Press. 


\section{Appendix}

Proof of Lemma 1. Assume there exists an equilibrium in which sellers separate on the price dimension. Note that in a separating equilibrium of our game the information about quality is conveyed by prices, so ads have no informative content. Hence, sellers optimally set zero coverage at a separating equilibrium because ads are costly and the advertising strategies $t$ and $d$ are not directly observable. Suppose indeed a separating equilibrium exists in which a seller advertises with some coverage (lower than one, because of the Inada conditions). Then, if she reduces the coverage, she saves on costs while leaving unaltered the buyer's perception about her quality, which is solely based on prices.

Proof of Lemma 2. Point $(i)$ follows directly from the fact that the equilibrium is symmetric and sellers are ex-ante identical in the buyer's eyes. Point (ii) follows straight from observing that

$$
\left.\begin{array}{l}
\operatorname{Pr}\left(\theta_{i}=\theta_{h} \mid s_{i}=h, s_{j}=\varnothing, \mathbf{p}\right)>\frac{1}{2}>\operatorname{Pr}\left(\theta_{j}=\theta_{h} \mid s_{i}=h, s_{j}=\varnothing, \mathbf{p}\right) \\
\operatorname{Pr}\left(\theta_{i}=\theta_{h} \mid s_{i}=\varnothing, s_{j}=h, \mathbf{p}\right)<\frac{1}{2}<\operatorname{Pr}\left(\theta_{j}=\theta_{h} \mid s_{i}=\varnothing, s_{j}=h, \mathbf{p}\right)
\end{array}\right\} \quad \Leftrightarrow \quad t^{*}>d^{*} .
$$

Point (iii). To organize the proof it is convenient to let the buyer make the conjecture that $t^{*}>d^{*}$ in equilibrium: being aware of the extra cost of deception $\phi$, a rational buyer anticipates that a low-quality seller will optimally choose a lower ads coverage than her high-quality rival. Such a conjecture, which we will verify ex-post, allows us to derive straightforwardly sellers' expected demands. The conjecture above is not necessary for the proof, as we will argue below, yet it permits a lighter treatment.

Given a pooling equilibrium price $p$ with $t_{i} \in(0,1)$ and $d_{i} \in(0,1)$ for $i \in\{1,2\}$, and denoting by $\boldsymbol{\alpha}(\cdot)=\left(\alpha_{1}\left(s_{1}, s_{2}\right), \alpha_{2}\left(s_{2}, s_{1}\right)\right)$ with $\alpha_{1}\left(s_{1}, s_{2}\right)+\alpha_{2}\left(s_{2}, s_{1}\right)=1$ the purchasing strategy of the buyer, expected demands for the high-quality seller, say seller 1 , and the low-quality seller, 2 , are

$$
\begin{aligned}
& D_{1}\left(t_{1}, t_{2}, d_{1}, d_{2}, \boldsymbol{\alpha}(\cdot)\right)=\alpha_{1}(h, h) t_{1} d_{2}+t_{1}\left(1-d_{2}\right)+\alpha_{1}(\varnothing, \varnothing)\left(1-t_{1}\right)\left(1-d_{2}\right), \\
& D_{2}\left(t_{1}, t_{2}, d_{1}, d_{2}, \boldsymbol{\alpha}(\cdot)\right)=\left(1-\alpha_{1}(h, h)\right) t_{1} d_{2}+\left(1-t_{1}\right) d_{2}+\left(1-\alpha_{1}(\varnothing, \varnothing)\right)\left(1-t_{1}\right)\left(1-d_{2}\right),
\end{aligned}
$$

where $\alpha_{1}(h, h)$ (resp. $\left.\alpha_{1}(\varnothing, \varnothing)\right)$ is the the probability that the buyer purchases from seller 1 when he observes two ads (resp. no ads); we have used point (ii) and the buyer's equilibrium conjecture $t^{*}>d^{*}$ to set $\alpha_{1}(h, \varnothing)=1$ and $\alpha_{1}(\varnothing, h)=0$. Expected profits are

$$
\begin{aligned}
& \pi_{1}\left(t_{1}, t_{2}, d_{1}, d_{2}, \boldsymbol{\alpha}(\cdot)\right)=D_{1}\left(t_{1}, t_{2}, d_{1}, d_{2}, \boldsymbol{\alpha}(\cdot)\right) p-c\left(t_{1}\right), \\
& \pi_{2}\left(t_{1}, t_{2}, d_{1}, d_{2}, \boldsymbol{\alpha}(\cdot)\right)=D_{2}\left(t_{1}, t_{2}, d_{1}, d_{2}, \boldsymbol{\alpha}(\cdot)\right) p-c\left(d_{2}\right)-\phi d_{2},
\end{aligned}
$$

and the system of first-order conditions is

$$
\begin{aligned}
c^{\prime}\left(t_{1}\right) & =\left[\alpha_{1}(h, h) d_{2}+\left(1-d_{2}\right)\left(1-\alpha_{1}(\varnothing, \varnothing)\right)\right] p, \\
c^{\prime}\left(d_{2}\right) & =\left[\left(1-\alpha_{1}(h, h)\right) t_{1}+\alpha_{1}(\varnothing, \varnothing)\left(1-t_{1}\right)\right] p-\phi,
\end{aligned}
$$

where, for ease of exposition, we omit the argument $p$ from $t_{1}(p)$ and $d_{2}(p)$. To pin down the buyer's equilibrium strategies, $\alpha_{1}(h, h)$ and $\alpha_{1}(\varnothing, \varnothing)$, take the alternative event that seller 1 has low quality and seller 2 has high quality. In this case, expected demands are defined similarly and the first-order 
conditions are

$$
\begin{aligned}
c^{\prime}\left(t_{2}\right) & =\left[\left(1-\alpha_{1}(h, h)\right) d_{1}+\left(1-d_{1}\right) \alpha_{1}(\varnothing, \varnothing)\right] p, \\
c^{\prime}\left(d_{1}\right) & =\left[\alpha_{1}(h, h) t_{2}+\left(1-\alpha_{1}(\varnothing, \varnothing)\right)\left(1-t_{2}\right)\right] p-\phi .
\end{aligned}
$$

Because of symmetry, in equilibrium it must hold $t_{1}=t_{2}=t$ and $d_{1}=d_{2}=d$, which implies $c^{\prime}\left(t_{1}\right)=$ $c^{\prime}\left(t_{2}\right)=c^{\prime}(t)$ and $c^{\prime}\left(d_{1}\right)=c^{\prime}\left(d_{2}\right)=c^{\prime}(d)$, yielding, respectively

$$
\begin{aligned}
& c^{\prime}(t)=\left\{\begin{array}{l}
{\left[\alpha_{1}(h, h) d+\left(1-\alpha_{1}(\varnothing, \varnothing)\right)(1-d)\right] p} \\
{\left[\left(1-\alpha_{1}(h, h)\right) d+\alpha_{1}(\varnothing, \varnothing)(1-d)\right] p}
\end{array}\right. \\
& c^{\prime}(d)=\left\{\begin{array}{l}
{\left[\left(1-\alpha_{1}(h, h)\right) t+\alpha_{1}(\varnothing, \varnothing)(1-t)\right] p-\phi} \\
{\left[\alpha_{1}(h, h) t+\left(1-\alpha_{1}(\varnothing, \varnothing)\right)(1-t)\right] p-\phi}
\end{array} .\right.
\end{aligned}
$$

Notice first that $t>d$ follows from (A1) and (A2) and the fact that $c(\cdot)$ is increasing. Which is consistent with the conjecture made earlier. Further, a slight manipulation of (A1) and (A2), yields, respectively

$$
\begin{aligned}
d\left(1-2 \alpha_{1}(h, h)\right) & =(1-d)\left(1-2 \alpha_{1}(\varnothing, \varnothing)\right), \\
t\left(1-2 \alpha_{1}(h, h)\right) & =(1-t)\left(1-2 \alpha_{1}(\varnothing, \varnothing)\right) .
\end{aligned}
$$

This system of equations is verified for generic $\alpha_{1}(h, h)$ and $\alpha_{1}(\varnothing, \varnothing)$ only if $t=d$, which violates (A1) and (A2). Hence, it must be $\alpha_{1}(h, h)=\alpha_{1}(\varnothing, \varnothing)=\frac{1}{2}$, which solves the system for any $t$ and $d$. This establishes that $\alpha_{i}^{*}(s, s)=1 / 2$ for every $i \in\{1,2\}$.

Going back to the conjecture $t^{*}>d^{*}$, it is clear from the above arguments that the opposite conjecture, $t^{*}<d^{*}$, would lead to a contradiction at the seller's optimization stage making the system of first-order conditions impossible to solve. For brevity, we omit the formal proof of the last statement. In conclusion, we have shown that, for $\phi>0$, the only possible equilibrium outcome is such that $t^{*}>d^{*}$ and $\alpha_{i}^{*}(s, s)=1 / 2$. Which concludes the proof of Lemma 2 .

Proof of Lemma 3. Using the results of Lemma 2, the first-order conditions of a high- and a low-quality seller at a symmetric pooling equilibrium become, respectively

$$
\begin{aligned}
c^{\prime}\left(t^{*}\right) & =\frac{p^{*}}{2}, \\
c^{\prime}\left(d^{*}\right) & =\frac{p^{*}}{2}-\phi,
\end{aligned}
$$

which, because $c(\cdot)$ is increasing and satisfies Inada conditions, clearly proves points $(i),(i i)$ and $(i i i)$ of the lemma. As to point $(i v)$ — which states that the profits of a high-quality seller, $\pi_{h}^{*}$, are higher than those of a low-quality seller, $\pi_{l}^{*}$ - notice that, if a symmetric pooling equilibrium with price $p^{*}>2 \phi$ 
exists, the following chain of inequalities holds

$$
\begin{aligned}
\pi_{h}^{*} & =\frac{p^{*}}{2}\left(1+t^{*}-d^{*}\right)-c\left(t^{*}\right) \\
& >\frac{p^{*}}{2}-c\left(d^{*}\right) \\
& \geq \frac{p^{*}}{2}-c\left(d^{*}\right)-\phi d^{*} \\
& >\frac{p^{*}}{2}\left(1-t^{*}+d^{*}\right)-c\left(d^{*}\right)-\phi d^{*}=\pi_{l}^{*},
\end{aligned}
$$

where the first inequality follows from setting $t^{*}=d^{*}$ and considering that this violates the optimality condition on the high-quality seller's profits, the second from the fact that $d^{*} \geq 0$ (because $p^{*} \geq 2 \phi$ ) and the third follows from observing that $t^{*}>d^{*}$. Thus

$$
\pi_{h}^{*}>\pi_{l}^{*}
$$

Finally, to prove point $(v)$, note that the buyer's expected utility from purchasing is minimal whenever he observes two identical ads or no ads at all. In such cases it equals the unconditional expectation $\mathrm{E}[\theta]$. Thus, if the customer buys under these circumstances, as implied by condition $p^{*} \leq \mathrm{E}[\theta]$, then he will always purchase in a pooling equilibrium with price equal to $p^{*}$ and the market does not break down. This concludes the proof of Lemma 3.

Proof of Proposition 1. Consider a symmetric pooling equilibrium in which sellers post the same price $p^{*}$ and the market never breaks down. By Lemmas 2 and 3, if it exists, a pooling equilibrium with deceptive advertising features $\alpha_{i}^{*}(h, h)=\alpha_{i}^{*}(\varnothing, \varnothing)=\frac{1}{2}, \alpha_{i}^{*}(h, \varnothing)=1$ and $\alpha_{i}^{*}(\varnothing, h)=0$, advertising strategies are $t^{*}=c^{-1}\left(\frac{p^{*}}{2}\right)$ and $d^{*}=c^{-1}\left(\frac{p^{*}}{2}-\phi\right)$, and the price satisfies $p^{*} \geq 2 \phi$. To prove existence we still have to prove that the buyer is willing to purchase at price $p^{*}$ (buyer's participation constraint) and that sellers make non negative profits (sellers' participation constraints) and are willing to charge the equilibrium price $p^{*}$ rather than a different price (sellers' incentive compatibility constraints).

As proved in Lemma 3, the buyer's participation constraint requires that, when he observes signals $\left(s_{i}, s_{j}\right) \in\{(h, h),(\varnothing, \varnothing)\}$ and his posteriors are 50-50, his expected utility from buying seller $i$ 's product exceeds the price. The buyer's participation constraint is then satisfied as long as

$$
p^{*} \leq \mathrm{E}[\theta] \quad \Leftrightarrow \quad \Delta \geq 2\left(p^{*}-\theta_{l}\right)
$$

which, because $p^{*} \geq 2 \phi$, yields the necessary condition

$$
\Delta \geq 2\left(2 \phi-\theta_{l}\right)
$$

Next, we analyze the seller's constraints. We have argued in the text that deviation profits do not depend on the type of the deviating firm. Notice first that a deviation must involve a change in price because advertising intensities are not directly observable and are chosen optimally. Hence, a seller's deviation that entails a change of the advertising intensity without altering the price would only reduce profits. As a consequence, a deviation must involve a price change to $p^{d} \neq p^{*}$. 
Under A1, a buyer observing the off-equilibrium price $p^{d}$ perceives the seller's good as low-quality and is thus ready to buy from her at a price no larger than $p^{*}-\Delta-$ i.e. the pooling price at which he believes he can purchase a high-quality good discounted by the quality differential $\Delta$. Hence, a seller willing to deviate must price at $p^{d} \leq p^{*}-\Delta$. Notice further that, under A1, advertising does not affect expected demand out of the equilibrium path and the best deviation a seller can choose is to charge a price $p^{d}=p^{*}-\Delta$ and stop advertising altogether. Thus, the highest profit guaranteed by a deviation is

$$
\pi^{d}\left(p^{*}\right)=p^{*}-\Delta
$$

which, as argued above, do not depend on the type of deviating seller. We should now notice that Lemma 3 implies that the expected profit of a high-quality seller is always higher than that of a lowquality seller at a symmetric pooling equilibrium. Thus, whenever a low-quality seller does not want to deviate, the high-quality seller does not deviate too. This implies, in turn, that the incentive compatibility constraint which is harder to meet is always that of the low-quality seller. Analogously, whenever the profit of the low-quality seller is non-negative, the profit of the high-quality seller is strictly positive, so we can focus on the participation constraint of the low-quality seller.

Summarizing, an equilibrium pooling price $p^{*}$ must satisfy the incentive and the participation constraints of the low-quality seller - i.e.,

$$
\pi_{l}^{*} \equiv \frac{p^{*}}{2}\left[1-t^{*}+d^{*}\right]-c\left(d^{*}\right)-\phi d^{*} \geq \max \left\{0, p^{*}-\Delta\right\} .
$$

We start by proving that the participation constraint is satisfied for any $p^{*}$ and, a fortiori, for $p^{*} \geq 2 \phi$. By optimality, this follows from

$$
\pi_{l}^{*} \geq \frac{p^{*}}{2}\left[1-t^{*}\right]>0
$$

where $\frac{p^{*}}{2}\left[1-t^{*}\right]$ is the profit of a low-quality seller at the pooling price $p^{*}$ when she sets deception level $d=0$ and the strict inequality follows from $0<t^{*}<1$ by the Inada condition - i.e., $c^{\prime}(1)$ large enough. Clearly, choosing optimally the advertising level, she can improve on the minimum profit of (A4). Thus, the only relevant constraint is the incentive compatibility one - i.e.,

$$
\pi_{l}^{*} \equiv \frac{p^{*}}{2}\left[1-t^{*}+d^{*}\right]-c\left(d^{*}\right)-\phi d^{*} \geq p^{*}-\Delta .
$$

We can immediately argue that, if $2 \phi<\Delta$, any price $p^{*} \in[2 \phi, \Delta]$ trivially satisfies this inequality: indeed deviation profits are negative - i.e. $p^{*}-\Delta \leq 0$. Hence, the maximal pooling price that satisfies (A5), $p(\phi, \Delta)$, must be greater than $\Delta$.

Let's thus focus on the most interesting case in which $2 \phi \geq \Delta$ and prove that, in this region of parameters, the incentive compatibility constraint is satisfied for $p^{*} \in[2 \phi, p(\phi, \Delta)]$ and that $p(\phi, \Delta)$ is unique. To this purpose, we will show that (A5) defines a non-empty set if the following conditions are satisfied:

1. $\left.\pi_{l}^{*}\right|_{p^{*}=2 \phi}>2 \phi-\Delta$

2. $\frac{\partial \pi_{l}^{*}}{\partial p^{*}}<1$ for any $p^{*}$. 
Essentially, point 1 implies that (A5) is satisfied at the minimum price $p^{*}=2 \phi$, while point 2 implies that (A5) is satisfied as an equality by a unique price $p(\phi, \Delta)$. We proceed point by point.

1. When $p^{*}=2 \phi,(\mathrm{A} 5)$ is satisfied if

$$
\left.\pi_{l}^{*}\right|_{p^{*}=2 \phi}=\phi\left(1-c^{\prime-1}(\phi)\right) \geq 2 \phi-\Delta
$$

which yields the necessary condition for (A5) to be satisfied at the minimum price, i.e.

$$
\Delta \geq \phi\left(1+c^{-1}(\phi)\right)
$$

2. For any $p^{*}$, the derivative of the low-quality seller's profit is

$$
\frac{\partial \pi_{l}^{*}}{\partial p^{*}}=\frac{1}{2}\left(1-t^{*}+d^{*}\right)-\frac{p^{*}}{4} \frac{1}{c^{\prime \prime}\left(t^{*}\right)}
$$

which is clearly lower than 1 because $0<d^{*}<t^{*}<1$ and $c^{\prime \prime}(\cdot)>0$.

Finally, define

$$
\bar{p}^{*}=\min \{p(\phi, \Delta), E[\theta]\},
$$

where $p(\phi, \Delta)$ is the unique solution to

$$
\pi_{l}^{*}=p^{*}-\Delta .
$$

Then, equation (A4), point 1 and point 2 taken together imply that the pooling prices of deceptive equilibria are $p^{*} \in\left[2 \phi, \bar{p}^{*}\right]$. In particular, equilibrium deceptive advertising $d^{*}$ is strictly positive as long as $p^{*}>2 \phi$. Vice versa, it is apparent that, if (A3) and (A6) are satisfied with strict inequality, any price equal to $2 \phi+\epsilon$ is a pooling equilibrium featuring positive deception provided $\epsilon>0$ is small enough. This concludes the proof.

Proof of Corollary 1. Clearly, when $\bar{p}^{*}=E[\theta]$, the maximal price increases with $E[\theta]$ and, because $E[\theta]=\theta_{l}+\frac{\Delta}{2}$, with $\Delta$. When, instead, $\bar{p}^{*}=p(\phi, \Delta)$, the result that $\bar{p}^{*}$ increases with $\Delta$ and decreases with $\phi$ follows immediately by a straightforward application of the Implicit Function Theorem.

Proof of Lemma 4. Notice that, for $p^{*} \in\left[2 \phi, \bar{p}^{*}\right]$, it holds

$$
\frac{\partial V^{*}\left(p^{*}\right)}{\partial p^{*}}=-1+\frac{\Delta}{2}\left(\frac{\partial t^{*}}{\partial p^{*}}-\frac{\partial d^{*}}{\partial p^{*}}\right)
$$

which can be rewritten as

$$
\frac{\partial V^{*}\left(p^{*}\right)}{\partial p^{*}}=-1+\frac{\Delta}{2 p^{*}}\left[\tilde{\varepsilon}_{t}\left(p^{*}\right)-\tilde{\varepsilon}_{d}\left(p^{*}\right)\right],
$$

from which the result follows immediately.

Proof of Proposition 2. Notice first that

$$
\frac{\partial V^{*}\left(p^{*}\right)}{\partial p^{*}}=-1+\frac{\Delta}{4}\left(\frac{1}{c^{\prime \prime}\left(t^{*}\right)}-\frac{1}{c^{\prime \prime}\left(d^{*}\right)}\right),
$$


which is clearly negative whenever $c^{\prime \prime \prime}(\cdot) \geq 0$ because $c^{\prime \prime}\left(t^{*}\right) \geq c^{\prime \prime}\left(d^{*}\right)$. Hence, because we focus on pooling equilibria with $p^{*} \geq 2 \phi$, it follows that $V^{*}\left(p^{*}\right)$ is maximized at $p^{*}=2 \phi$.

Suppose instead that $c^{\prime \prime \prime}(\cdot)<0$. Then, to show that the price maximizing $V^{*}\left(p^{*}\right)$ is above $2 \phi$ it suffices to show that $\frac{\partial V^{*}\left(p^{*}\right)}{\partial p^{*}}>0$ at $p^{*}=2 \phi$ - i.e., rearranging (A7),

$$
\left.\frac{\partial V^{*}\left(p^{*}\right)}{\partial p^{*}}\right|_{p^{*}=2 \phi}>0 \quad \Leftrightarrow \quad \Delta>\left.\frac{4 c^{\prime \prime}\left(d^{*}\right) c^{\prime \prime}\left(t^{*}\right)}{c^{\prime \prime}\left(d^{*}\right)-c^{\prime \prime}\left(t^{*}\right)}\right|_{p^{*}=2 \phi} .
$$

This completes the proof.

Proof of Lemma 5. Notice that, for $p^{*} \in\left[2 \phi, \bar{p}^{*}\right]$, it holds

$$
\frac{\partial \pi^{*}\left(p^{*}\right)}{\partial p^{*}}=\frac{1}{2}\left[1-\frac{1}{2}\left(\frac{c^{\prime}\left(t^{*}\right)}{c^{\prime \prime}\left(t^{*}\right)}+\frac{c^{\prime}\left(d^{*}\right)+\phi}{c^{\prime \prime}\left(d^{*}\right)}\right)\right]
$$

which can be rewritten as

$$
\frac{\partial \pi^{*}\left(p^{*}\right)}{\partial p^{*}}=\frac{1}{2}\left[1-\frac{1}{2}\left(\tilde{\varepsilon}_{t}\left(p^{*}\right)+\tilde{\varepsilon}_{d}\left(p^{*}\right)\right)\right],
$$

from which the result follows immediately.

Proof of Proposition 3. Noticing that

$$
\tilde{\varepsilon}_{t}\left(p^{*}\right)=\frac{c^{\prime}\left(t^{*}\right)}{c^{\prime \prime}\left(t^{*}\right)} \quad \text { and } \quad \tilde{\varepsilon}_{d}\left(p^{*}\right)=\frac{c^{\prime}\left(t^{*}\right)}{c^{\prime \prime}\left(d^{*}\right)}
$$

it is easy to show that

$$
\frac{\partial \pi^{*}}{\partial p^{*}}>0 \quad \Leftrightarrow \quad \rho\left(t^{*}\right)<2 \frac{c^{\prime \prime}\left(d^{*}\right)}{c^{\prime \prime}\left(t^{*}\right)+c^{\prime \prime}\left(d^{*}\right)}
$$

Now define

$$
\begin{aligned}
r & \equiv \min _{0 \leq d^{*}<t^{*}<1} 2 \frac{c^{\prime \prime}\left(d^{*}\right)}{c^{\prime \prime}\left(t^{*}\right)+c^{\prime \prime}\left(d^{*}\right)}, \\
R & \equiv \max _{0 \leq d^{*}<t^{*}<1} 2 \frac{c^{\prime \prime}\left(d^{*}\right)}{c^{\prime \prime}\left(t^{*}\right)+c^{\prime \prime}\left(d^{*}\right)},
\end{aligned}
$$

and notice that, because $c^{\prime \prime}(x)>0$ for all $x \in[0,1], r$ and $R$ are well defined. Then, clearly, a sufficient condition for $\pi_{h}^{*}$ and $\pi_{l}^{*}$ to be increasing (resp. decreasing) in $p^{*}$ is that $\rho(x)<r$ (resp. $\rho(x)>R$ ) for all $0 \leq x<1$.

Proof of Corollary 2. Consider pooling equilibria. By Proposition $2, c^{\prime \prime \prime}(\cdot)<0$ implies that the buyer's surplus is maximized at a price larger than $2 \phi$, while seller's preferred price is the highest possible price because $\rho(x)<r$ for every $x \in[0,1]$. Thus, any price $p<2 \phi$ cannot be Pareto efficient.

Proof of Proposition 4. Clearly, given A2, the high-quality seller does not want to deviate: charging a price above $\Delta$ makes the buyer prefer purchasing from the low-quality seller at price 0 , while pricing below simply reduces profits. Likewise, advertising has no effect other than increasing costs. As to the low-quality seller, as argued in the text, the only meaningful deviation given $\mathbf{A 2}$ is to price at $\Delta$ and optimally set ads given that the high-quality seller, sticking to the equilibrium strategy, will set no ads. 
In particular, again by $\mathbf{A 2}$, it is optimal not to advertise off-equilibrium. In this case, deviation profits of the low-quality seller are

$$
\pi_{l}^{d}=\left\{\begin{array}{c}
\frac{\Delta}{2} \quad \Leftrightarrow \quad \mathrm{E}[\theta] \geq \Delta \\
0 \quad \Leftrightarrow \quad \mathrm{E}[\theta]<\Delta
\end{array}\right.
$$

where the first raw (resp. second) applies when the buyer's participation constraint off-equilibrium does not (resp. does) bind. Clearly, a separating equilibrium exists if and only if condition (16) is met.

Proof of Proposition 5. The proof follows exactly the same lines of that of Proposition 1 with the only difference that, because $p^{* *} \leq 2 \phi$, the optimal coverage chosen by a low-quality seller is $d^{* *}=0$ and thus the message $\left(s_{i}, s_{j}\right)=(h, h)$ is never received in equilibrium.

Proof of Proposition 6. Focus first on prices $p^{* *} \in[0,2 \phi]$. Then $\pi^{* *}\left(p^{* *}\right)$ is increasing for all $p^{* *}$ if and only if

$$
\tilde{\varepsilon}_{t}\left(p^{* *}\right)<2 \quad \forall p^{* *} \in[0,2 \phi]
$$

which is true if

$$
\max _{t^{* *} \in\left[0, c^{-1}(\phi)\right]} \frac{c^{\prime}\left(t^{* *}\right)}{c^{\prime \prime}\left(t^{* *}\right)}<2 .
$$

Notice that, because $c^{\prime \prime}\left(t^{* *}\right)>0$ for all $t^{* *}, c^{\prime \prime \prime}(\cdot)$ has a constant sign, and $c^{\prime}\left(t^{* *}\right)=\phi$ when $t^{* *}=c^{\prime-1}(\phi)$, the above condition can be rewritten as

$$
\phi<2 \min \left\{c^{\prime \prime}(0), c^{\prime \prime}\left(c^{-1}(\phi)\right)\right\}
$$

Let's now focus on $p^{*} \geq 2 \phi$ and study the marginal increase of $\pi^{*}\left(p^{*}\right)$ in a right-neighborhood of $p^{*}=2 \phi$. We will show that, if profits are increasing locally at $p^{*}=2 \phi-$ i.e. $\tilde{\varepsilon}_{t}(2 \phi)+\tilde{\varepsilon}_{d}(2 \phi)<2$ - then profits are also increasing for prices below $2 \phi$ - i.e. (A8) holds. Profits are increasing at $p^{*}=2 \phi$ if

$$
\tilde{\varepsilon}_{t}(2 \phi)+\tilde{\varepsilon}_{d}(2 \phi)=\phi\left(\frac{1}{c^{\prime \prime}\left(c^{\prime-1}(\phi)\right)}+\frac{1}{c^{\prime \prime}(0)}\right)<2 \quad \Leftrightarrow \quad \phi<2 \frac{c^{\prime \prime}\left(c^{\prime-1}(\phi)\right) c^{\prime \prime}(0)}{c^{\prime \prime}\left(c^{\prime-1}(\phi)\right)+c^{\prime \prime}(0)}
$$

Finally notice that (A9) implies (A8). In fact (A9) can be rewritten as

$$
\phi<2 \min \left\{c^{\prime \prime}(0), c^{\prime \prime}\left(c^{\prime-1}(\phi)\right)\right\} \frac{\max \left\{c^{\prime \prime}(0), c^{\prime \prime}\left(c^{-1}(\phi)\right)\right\}}{c^{\prime \prime}(0)+c^{\prime \prime}\left(c^{\prime-1}(\phi)\right)}<2 \min \left\{c^{\prime \prime}(0), c^{\prime \prime}\left(c^{-1}(\phi)\right)\right\},
$$

where the latter inequality proves the claim.

Proof of Proposition 7. First, notice that sellers can coordinate on a pooling equilibrium only if $\Delta\left(\phi, \theta_{l}\right)<\Delta$ (see Proposition 1 ). Second, a sufficient condition for sellers to be willing to coordinate on a pooling equilibrium with deception rather than on a separating equilibrium is $\pi^{*}(2 \phi)>\pi^{s}$ - i.e.,

$$
\frac{2 \phi-c\left(c^{-1}(\phi)\right)}{2}>\frac{\Delta}{2}
$$

which, together with the former condition, completes the proof.

Of course, condition (22) may define an empty set. To show that there are cases in which this condition is not vacuous, consider the case in which the penetration cost is quadratic, $c(x)=k x^{2} / 2$. 
Under this specification one can show (see the 'Quadratic cost function' paragraph at the end of the Appendix) that

$$
\pi^{*}(2 \phi)-\pi^{s}=\frac{\phi}{2 k}(4 k-\phi)-\frac{\Delta}{2}>0 \quad \Leftrightarrow \quad \Delta<\frac{\phi}{2 k}(4 k-\phi) .
$$

This inequality is compatible with condition (8) that guarantees the existence of pooling equilibria with deceptive advertising. For example, in the region of parameters in which $\theta_{l}$ is such that

$$
\underline{\Delta}\left(\phi, \theta_{l}\right)=\frac{\phi}{k}(k+\phi),
$$

then (8) and (A10) are jointly satisfied as long as

$$
\frac{\phi}{k}(k+\phi)<\Delta<\frac{\phi}{2 k}(4 k-\phi)
$$

which is always non-empty if $\phi \leq \frac{2}{3} k$.

Proof of Proposition 8. Let's find first a sufficient condition for (23). Notice that

$$
\pi^{* *}\left(p^{* *}\right)=\frac{p^{*}}{2}\left(1-\frac{p^{*}}{8 k}\right)
$$

and

$$
\max _{p^{* *} \in(0,2 \phi]} \pi^{* *}\left(p^{* *}\right)=\phi\left(1-\frac{\phi}{4 k}\right)
$$

So, recalling that $\pi^{s}=\frac{\Delta}{2}$,

$$
\pi^{s}>\max _{p^{* *} \in(0,2 \phi]} \pi^{* *}\left(p^{* *}\right) \quad \Leftrightarrow \quad \Delta>\frac{\phi}{2 k}(4 k-\phi)
$$

which defines a lower bound for $\Delta$.

Let's now turn to the sufficient condition for (24). Notice that $V^{s}=\theta_{l}$, while

$$
\begin{aligned}
V\left(\bar{p}^{*}\right) & =\mathrm{E}[\theta]-\bar{p}^{*}+\frac{\Delta}{2} \frac{\phi}{k} \\
& =\theta_{l}+\frac{\Delta}{2}\left(1+\frac{\phi}{k}\right)-\bar{p}^{*} \\
& >\theta_{l}+\frac{\Delta}{2}\left(1+\frac{\phi}{k}\right)-2 k
\end{aligned}
$$

where the inequality comes from the Inada conditions (in fact, as shown in the 'Quadratic cost function' paragraph at the end of the Appendix, $\left.t^{*}=\frac{p^{*}}{2 k}<1 \Leftrightarrow p^{*}<2 k\right)$. Thus, a sufficient condition for $V^{s}<V\left(\bar{p}^{*}\right)$ is

$$
\theta_{l}<\theta_{l}+\frac{\Delta}{2}\left(1+\frac{\phi}{k}\right)-2 k \quad \Leftrightarrow \quad \Delta>4 \frac{k^{2}}{k+\phi}
$$


which defines another lower bound for $\Delta$. Thus, conditions (23) and (24) are jointly met if

$$
\Delta>\max \left\{\frac{\phi}{2 k}(4 k-\phi), \frac{4 k^{2}}{k+\phi}\right\}
$$

this concludes the proof.

Proof of Proposition 9. To begin with, notice that from the first-order condition (26)

$$
e^{\prime}\left(\phi^{b}\right)=\frac{\partial \bar{p}^{*}}{\partial \phi}\left[-1+\frac{\Delta}{4} \frac{\partial}{\partial \bar{p}^{*}}\left[t^{*}\left(\bar{p}^{*}\right)-d^{*}\left(\bar{p}^{*}, \phi\right)\right]\right]-\left.\frac{\Delta}{4} \frac{\partial d^{*}\left(\bar{p}^{*}, \phi\right)}{\partial \phi}\right|_{\phi=\phi^{b}} .
$$

Next, substituting this expression into the first-order condition of the total welfare maximization problem evaluated at $\phi^{b}$ one can immediately verify that

$$
\left.\frac{d W\left(\bar{p}^{*}, \phi\right)}{d \phi}\right|_{\phi=\phi^{b}}=-2 \frac{\partial \bar{p}^{*}}{\partial \phi} \frac{\partial \pi^{*}\left(\bar{p}^{*}, \phi\right)}{\partial p^{*}}-\left.c^{\prime}\left(d^{*}\left(\bar{p}^{*}, \phi\right)\right) \frac{\partial d^{*}\left(\bar{p}^{*}, \phi\right)}{\partial \phi}\right|_{\phi=\phi^{b}} .
$$

Recall that we have assumed that $\partial \pi^{*}\left(p^{*}, \phi\right) / \partial p^{*}>0$ for every $p^{*}$. Moreover, from the first-order condition (7) it follows that $\partial d^{*}\left(\bar{p}^{*}, \phi\right) / \partial \phi<0$. Hence, since $\partial \bar{p}^{*} / \partial \phi \leq 0$ from Corollary 1, it follows that

$$
\left.\frac{d W\left(\bar{p}^{*}, \phi\right)}{d \phi}\right|_{\phi=\phi^{b}}>0 .
$$

Hence, by concavity of $W\left(\bar{p}^{*}, \phi\right)$ with respect to $\phi$, it follows that $\phi^{b}<\phi^{w}$.

Proof of Proposition 10. Given that we wish to prove existence, we simplify the proof of this extension with respect to that of Proposition 1. We assume that the equilibrium is that described in the proposition and then prove that actually it is an equilibrium. By Bayes' rule and using symmetry, the equilibrium beliefs are

$$
\begin{aligned}
\operatorname{Pr}\left(\theta_{i}=\theta_{l} \mid h, h, \mathbf{p}^{*}\right) & =\frac{1}{2} \frac{\varrho d^{*}}{(1-\varrho) t_{h}^{*}+\varrho d^{*}}, \\
\operatorname{Pr}\left(\theta_{i}=\theta_{l} \mid \varnothing, h, \mathbf{p}^{*}\right) & =\frac{\varrho t_{H}^{*}\left(1-d^{*}\right)}{\left(t_{h}^{*}(1-\varrho)+\varrho d^{*}\right)\left(1-t_{H}^{*}\right)+\left(1-t_{h}^{*}(1-\varrho)-\varrho d^{*}\right) t_{H}^{*}}, \\
\operatorname{Pr}\left(\theta_{i}=\theta_{l} \mid h, \varnothing, \mathbf{p}^{*}\right) & =\frac{\varrho\left(1-t_{H}^{*}\right) d^{*}}{\left(t_{h}^{*}(1-\varrho)+\varrho d^{*}\right)\left(1-t_{H}^{*}\right)+\left(1-t_{h}^{*}(1-\varrho)-\varrho d^{*}\right) t_{H}^{*}}, \\
\operatorname{Pr}\left(\theta_{i}=\theta_{l} \mid \varnothing, \varnothing, \mathbf{p}^{*}\right) & =\frac{1}{2} \frac{\varrho\left(1-d^{*}\right)}{1-(1-\varrho) t_{h}^{*}-\varrho d^{*}}
\end{aligned}
$$

Notice that

$$
\operatorname{Pr}\left(\theta_{i}=\theta_{l} \mid h, \varnothing, \mathbf{p}^{*}\right)<\operatorname{Pr}\left(\theta_{i}=\theta_{l} \mid \varnothing, h, \mathbf{p}^{*}\right),
$$

if and only if $t_{H}^{*}>d^{*}$. That is, it is more likely that the seller has low quality if she does not post an ad, rather than if she does, provided that the surely high-quality seller does more advertising than the low-quality one. If this last condition holds, it is more likely that a seller is of bad quality if the buyer 
does not observe any ad rather than in the case he observes an ad from each seller, that is,

$$
\operatorname{Pr}\left(\theta_{i}=\theta_{l} \mid \varnothing, \varnothing, \mathbf{p}^{*}\right)>\operatorname{Pr}\left(\theta_{i}=\theta_{l} \mid h, h, \mathbf{p}^{*}\right)
$$

Let us now determine the optimal advertising strategies of the sellers. Given the behavior strategy of the buyer, expected profits of a seller with type, respectively, $H, h$ and $l$ are

$$
\begin{aligned}
\pi_{H} & =\frac{1}{2}\left(1+t_{H}-\varrho d-(1-\varrho) t_{h}\right) p-c\left(t_{H}\right), \\
\pi_{h} & =\frac{1}{2}\left(1+t_{h}-t_{H}\right) p-c\left(t_{h}\right), \\
\pi_{l} & =\frac{1}{2}\left(1+d-t_{H}\right) p-c(d)-\phi d,
\end{aligned}
$$

and the system of first-order conditions is

$$
c^{\prime}\left(t_{H}^{*}\right)=\frac{p^{*}}{2}, \quad c^{\prime}\left(t_{h}^{*}\right)=\frac{p^{*}}{2}, \quad c^{\prime}\left(d^{*}\right)=\frac{p^{*}}{2}-\phi
$$

it turns out that it must be

$$
c^{\prime}\left(t^{*}\right)=\frac{p^{*}}{2}, \quad c^{\prime}\left(d^{*}\right)=\frac{p^{*}}{2}-\phi,
$$

where $t_{H}^{*}=t_{h}^{*}=t^{*}$. Notice that $t^{*}>d^{*}$, and hence (A12) is satisfied. Thus, equilibrium profits are

$$
\begin{aligned}
\pi_{H}^{*} & =\frac{p^{*}}{2}\left(1+\varrho\left(t^{*}-d^{*}\right)\right)-c\left(t^{*}\right), \\
\pi_{h}^{*} & =\frac{p^{*}}{2}-c\left(t^{*}\right), \\
\pi_{l}^{*} & =\frac{p^{*}}{2}\left(1-t^{*}+d^{*}\right)-c\left(d^{*}\right)-\phi d^{*},
\end{aligned}
$$

with $\pi_{H}^{*}>\pi_{h}^{*}>\pi_{l}^{*}$. The first inequality is trivial. As for the second, notice that using repeatedly the first-order conditions for the advertising strategies we have

$$
\pi_{h}^{*}-\pi_{l}^{*}=-c\left(t^{*}\right)+c^{\prime}\left(t^{*}\right) t^{*}+c\left(d^{*}\right)-c^{\prime}\left(d^{*}\right) d^{*}>0,
$$

where the last inequality is equivalent to

$$
c\left(d^{*}\right)-c^{\prime}\left(d^{*}\right) d^{*}>c\left(t^{*}\right)-c^{\prime}\left(t^{*}\right) t^{*}
$$

which is satisfied because $t^{*}>d^{*}$ and $c(x)-x c^{\prime}(x)$ is decreasing in $x$ - since its first derivative is: $-c^{\prime \prime}(x) x<0$.

Now we have to check the buyer's strategies. Given the assumption of symmetry, whenever the buyer receives the same signal (high-quality or no signal) he is indifferent between the two sellers. Hence, any probability distribution about purchases is an equilibrium one, provided that the participation constraint is satisfied. In particular, $\alpha_{i}^{*}(h, h)=\alpha_{i}^{*}(\varnothing, \varnothing)=\frac{1}{2}$ for every $i=1,2$ is an equilibrium strategy. If the buyer receives an ad from only one seller the buyer will purchase from that seller, since (A12) holds. 
Given the above results (i.e., $\pi_{H}^{*}>\pi_{h}^{*}>\pi_{l}^{*}$ ) and deviation profits which are also in this case $\pi^{d}=p^{*}-\Delta$ for any type of seller, the only participation and incentive compatibility constraints to be checked are those of $l$. Thus, noticing that the equilibrium profit of the $l$ type is unchanged relative to the perfect correlation case, the characterization is identical to that of Proposition 1. Notice however that equilibrium beliefs are now different and more importantly profits of type $H$ are increasing in $\varrho$ (since $d^{*}$ is independent from $\varrho$ ).

Quadratic cost function. Suppose the cost function is $c(x)=k \frac{x^{2}}{2}$ with $k>0$. Notice first that $c^{\prime \prime}(x)=k$ and $c^{\prime \prime \prime}(x)=0$. Then

$$
\begin{aligned}
t^{*} & =\frac{p^{*}}{2 k}, \\
d^{*} & =\frac{p^{*}}{2 k}-\frac{\phi}{k},
\end{aligned}
$$

and notice that $1>t^{*}>d^{*}>0$ requires $k>\frac{p^{*}}{2}>\phi$ so that a necessary condition for the existence of pooling equilibria with deceptive advertising is $k>\phi$.

Note that, in a pooling equilibrium with deception it holds

$$
\varepsilon_{t}\left(p^{*}\right)+\varepsilon_{t}\left(p^{*}\right)=t^{*}+d^{*}<2,
$$

which, evaluated at $p^{*}=2 \phi$, becomes

$$
\frac{\phi}{k}<2
$$

which is always true given $k>\phi$. Thus Proposition 6 applies to the quadratic case. It is immediate to check that equilibrium profits are increasing in the pooling price also for $p^{* *}<2 \phi$.

The condition under which ex-ante profits in separating are lower that ex-ante profits in pooling is that $\pi^{*}(2 \phi)>\pi^{s}$. Profits are

$$
\begin{aligned}
\pi^{s} & =\frac{\Delta}{2} \\
\pi^{*}\left(p^{*}\right) & =\frac{1}{2}\left[p^{*}\left(1-\frac{p^{*}}{4 k}\right)+\frac{\phi^{2}}{2 k}\right]
\end{aligned}
$$

so that

$$
\pi^{*}(2 \phi)>\pi^{s} \quad \Leftrightarrow \quad \Delta<\frac{\phi}{2 k}(4 k-\phi)
$$

which is condition (A10).

The existence condition of pooling equilibria, condition (8), provided the participation constraint is satisfied so that $\underline{\Delta}\left(\phi, \theta_{l}\right)=\phi\left(1+c^{-1}(\phi)\right)$, boils down to

$$
\Delta>\Delta\left(\phi, \theta_{l}\right) \quad \Leftrightarrow \quad \Delta>\frac{\phi}{k}(k+\phi) .
$$


Thus, condition (22) defines a non empty set as long as

$$
\frac{\phi}{2 k}(4 k-\phi)>\frac{\phi}{k}(k+\phi) \Leftrightarrow \quad \Leftrightarrow<\frac{2}{3} k .
$$

Notice finally that (8) is not satisfied if

$$
\Delta<\frac{\phi}{k}(k+\phi) \Longleftarrow \phi>\frac{k}{2}\left[\sqrt{1+\frac{4 \Delta}{k}}-1\right],
$$

as noted in the text. 
1. L. Colombo, H. Dawid, Strategic Location Choice under Dynamic Oligopolistic Competition and Spillovers, Novembre 2013.

2. M. Bordignon, M. Gamalerio, G. Turati, Decentralization, Vertical Fiscal Imbalance, and Political Selection, Novembre 2013.

3. M. Guerini, Is the Friedman Rule Stabilizing? Some Unpleasant Results in a Heterogeneous Expectations Framework, Novembre 2013.

4. E. Brenna, C. Di Novi, Is caring for elderly parents detrimental to women's mental health? The influence of the European North-South gradient, Novembre 2013.

5. F. Sobbrio, Citizen-Editors' Endogenous Information Acquisition and News Accuracy, Novembre 2013.

6. P. Bingley, L. Cappellari, Correlation of Brothers Earnings and Intergenerational Transmission, Novembre 2013.

7. T. Assenza, W. A. Brock, C. H. Hommes, Animal Spirits, Heterogeneous Expectations and the Emergence of Booms and Busts, Dicembre 2013.

8. D. Parisi, Is There Room for 'Fear' as a Human Passion in the Work by Adam Smith?, Gennaio 2014.

9. E. Brenna, F. Spandonaro, Does federalism induce patients' mobility across regions? Evidence from the Italian experience, Febbraio 2014.

10. A. Monticini, F. Ravazzolo, Forecasting the intraday market price of money, Febbraio 2014.

11. Tiziana Assenza, Jakob Grazzini, Cars Hommes, Domenico Massaro, $P Q$ Strategies in Monopolistic Competition: Some Insights from the Lab, Marzo 2014.

12. R. Davidson, A. Monticini, Heteroskedasticity-and-Autocorrelation-Consistent Bootstrapping, Marzo 2014.

13. C. Lucifora, S. Moriconi, Policy Myopia and Labour Market Institutions, Giugno 2014.

14. N. Pecora, A. Spelta, Shareholding Network in the Euro Area Banking Market, Giugno 2014.

15. G. Mazzolini, The economic consequences of accidents at work, Giugno 2014.

16. M. Ambrosanio, P. Balduzzi, M. Bordignon, Economic crisis and fiscal federalism in Italy, Settembre 2014.

17. P. Bingley, L. Cappellari, K. Tatsiramos, Family, Community and Long-Term Earnings Inequality, Ottobre 2014.

18. S. Frazzoni, M. L. Mancusi, Z. Rotondi, M. Sobrero, A. Vezzulli, Innovation and export in SMEs: the role of relationship banking, Novembre 2014.

19. H. Gnutzmann, Price Discrimination in Asymmetric Industries: Implications for Competition and Welfare, Novembre 2014.

20. A. Baglioni, A. Boitani, M. Bordignon, Labor mobility and fiscal policy in a currency union, Novembre 2014.

21. C. Nielsen, Rational Overconfidence and Social Security, Dicembre 2014.

22. M. Kurz, M. Motolese, G. Piccillo, H. Wu, Monetary Policy with Diverse Private Expectations, Febbraio 2015.

23. S. Piccolo, P. Tedeschi, G. Ursino, How Limiting Deceptive Practices Harms Consumers, Maggio 2015.

24. A.K.S. Chand, S. Currarini, G. Ursino, Cheap Talk with Correlated Signals, Maggio 2015. 
25. S. Piccolo, P. Tedeschi, G. Ursino, Deceptive Advertising with Rational Buyers, Giugno 2015. 